\title{
CRYOPUMP BEHAVIOR IN THE PRESENCE OF BEAM OR NUCLFAR RADIATION
}

\author{
Peter K. Law \\ Lawrence Berkeley Laboratory \\ Berkeley, California 94720
}


CRYOPUMP BEHAVIOR IN THE PRESENCE OF BEAM OR

NUCLEAR RADIATION

Peter K. Law

\section{Contents}

Abstract...............................111

I. Introduction.........................

A. Impurity Effects in Fusion Reactor

Operations........................

B. Cryocondensation Pumping for Neutral

Beam Injectors.................... 4

C. Pumping Speed Requirements for TFTR

3-Source Beamline.................. 6

II. Known Properties of Hydrogen and Deuterlum

Applicable to Cryocondensation Pumping....... 7

A. Triple Point....................... 7

B. Vapor Pressure.................... 8

c. Liquid and Solid Densities.............. 9

III. Description of a Test Cryopump for TFTR....... 10

A. Cryopump Construction................ 10

B. Measuring systens................. 12

IV. Test Cryopump Measurements............... 14

A. Static Pumping Data................. 15 
B. Dynamic Pumping Speed Measurements......... 16

C. Beam Desorption Experiment............. 17

v. Neutron Desorption and Reactor Flux Dlagnostics... 18

A. Introduction. ..................... 18

B. Berkeley Research Experiment..............20

c. Reactor Pulse Measurements............... 21

vi. Concluston.......................... 27

Appendices........................... 28

Figures............................ 30

References.............................64 
Cryocondensation pumping has been proposed to be the method of gas removal for neutral-beam refueled fusion reactors. A cryocondensation pumping unit has been constructed to test design concepts and compatibility with conditions under actual beam operation and nuclear radiation environment.

Various operating parameters for this test pumping unit have been measured, including pumping speeds for various gases and beam desorption effects.

An experiment has been planned at the Berkeley Research Reactor to measure the desorption effects of high energy neutrons and gamma radiation. A foll activation method has been devised to accurately assess the energy spectrum of this neutron source, which is expected to be comparable to that of the Tokamak Fusion Test Reactor. 


\section{Introduction}

The attainment and maintenance of high vacuum in a thermonuclear fusion device is essentlal due to the existence of serious energy-loss mechanisms that would otherwise occur. Many aspects of the vacuum problem are being investigated, such as vacuum-wall materlals research, 1 desorption effects, ${ }^{2}$ sublimation pumplng, ${ }^{3}$ and better materlals fabrication and prépararion methods. 4

In paits further removed from the plasma, especially Inside neutral-beam injection ducts where very large gas-load removal is required, 5 cryocondensation pumping will be the primary means of gas and 1mpurity removal. Cryopumping is the only cholce for this. purpose because of its high pumplng speed and almost total absence of contamination, even given the chance of fallure. ${ }^{6}$ However, much Information about condensed gas behavior, design parameters, and experience with operation under varlous conditions must be made avaliable before large cryopumps can be incorporatea into a thermonuclear fusion device.

\section{A. Impurity Effects In Fusion Reactor Operations}

High atomic number Impuritles sputtered and blistered off vacuum walls, and cold background gases from varlous sources, particularly neutral beam injectors, if not removed, would result in driving up both the Ignition condition and the Lawson criterton. 
The energy-loss mechanisms include Impurity-driven instabilities, radiation emission, 8 and greater fuel requirements through more Intense neutral beam infection and ohmic heating.

The 1 gnition condition of a steady-state homogeneous D-T reactor 1B given by 9

$$
\left.\frac{3}{2}\left(n_{e} k T_{e}+\sum_{1} n_{1} k T_{1}\right)=(<\sigma v\rangle u_{\alpha} n_{D} n_{T}-p_{r a d}\right) \tau
$$

where

$$
\begin{aligned}
& \text { <ov> - D-T reaction rate average over a Maxwellian } \\
& \text { energy distribution } \\
& v_{a} \quad-\quad 3.52 \mathrm{MeV} \text { (assuming complete energy deposition } \\
& \text { In plasma by alpha particle). } \\
& \text { fne - concentration of single impurity spectes of } \\
& \text { atomic number } z \text { which is fully lonized }
\end{aligned}
$$

and

$$
\begin{aligned}
P_{\text {rad }}= & R(f, z, T) n_{e}{ }^{2}=\text { radiated power, which includes } \\
& \text { free-free bremsstrahlung, recombination and } \\
& \text { line radiation. }
\end{aligned}
$$

Under these conditions, the ignition condition can be written as, assuming $\mathrm{T}_{e}=\mathrm{T}_{1}=\mathrm{T}$,

$$
n_{\ell} \tau=\frac{\frac{3}{2} k T[1+(1-f z)+f]}{\frac{s \sigma v>}{4} U(1-z f)^{2}-\frac{R(1-n)}{n}}
$$

and the Lawson criterion as 


$$
n_{l} \tau=\frac{3 k T[I+(I-f z)+f] \frac{(1-\eta)}{2 \eta}}{\frac{\langle\sigma v>}{4} U_{t}(I-z r)^{2}-\frac{R(1-\eta)}{n}}
$$

and the Lawson criterion as

where $U_{t}=$ total energy released $=22.4 \mathrm{MeV}$

and $\eta$ - thermal conversion efficiency $=0.3$

The extent of power loss from the plasma due to these impurities can be estimated from the following equations:

For free-free bremsstrahlung, power-loss is given by

$$
P_{B}=4.86 \times 10^{-30} \mathrm{n}_{\mathrm{T}^{\mathrm{T}}}^{1 / 2} \frac{\mathrm{i}^{z_{i}{ }^{2} \mathrm{n}_{i} \mathrm{E}_{f f}\left(\mathrm{z}^{2} / \mathrm{T}\right)}}{\mathrm{z}_{i} \mathrm{z}_{i}}\left(\mathrm{~W} / \mathrm{cm}^{3}\right)
$$

where $g_{f f}$ if the Gaunt factor to correct for quantum effects, and is a function of the Ion temperature and impurity ion species. Values of $B_{f f}$ are given by Karzaz and Latter. 10

Recombination radiation generated between highly-stripped, high $z$ Ions and plastna electrons, 11 and 1 ine radiation loss $^{12}$ from transitions of the type $\Delta n=0$ in not fully ionized atoms, are given by

$$
\begin{aligned}
& P_{R} \cong 1.3 \times 10^{-32}+\frac{\mathrm{z}^{4}}{\mathrm{~T}_{\mathrm{e}}^{1 / 2} \mathrm{n}_{\mathrm{e}}^{2}} \quad\left(\mathrm{~W} / \mathrm{cm}^{3}\right) \\
& P_{L} \cong 2 \times 10^{-26} \mathrm{fn}_{\mathrm{e}}^{2} \quad\left(\mathrm{~W} / \mathrm{cm}^{3}\right)
\end{aligned}
$$

respectively.

In addition to creating increased radiative cooling and Increasing operating temperatures, gas atoms and high 2 impurities can create a much more detrimental effect by accumulating on the 
plaswa periphery and inducing a beam-deposition instability. ${ }^{13}$ chargeexchange between cold background gases, mainly from the lon source of neutral beam infectors, together with the high 2 impurities sputtered off racuum walls, will create an effective impurity layer, 11mItIng neutral beam deposition through the sequential process of local heating, charge exchange, more sputtering of wall material, and further 1mpact Ionization of the neutral beam. Hork in this erea by Post et 01.13 and Girard et al. 14 has been particularly 11luminating. This impurity-driven Instability, coupled with the Inevitable $10 \%$ loss of neutral beam power through charge-exchange, 15 mght severely limit neutral beam penetration. Many methods have been suggested to alleviate the problem of Impurities, ${ }^{16-18}$ but In the case of cold streaming deuterium gas from neutral beam injectors, differential pumping ${ }^{19}$ using cryocondensation pumping at ILquid hellum temperatures is the only feasible method.

\section{B. Eryocondensation Pumping for Neutral Beam Injectors}

The recent success of neutral beam injection has placed great demand on improved vacuum systems and techniques, particularly in the form of cryocondensation pumping. 5

The reasons for choosing cryopumping over other methods are many: Ion pumps give pumping speeds too $\mathbf{s m a l 1}$ to be effective, and ofl diffusion pumps are $b I_{g}$ and costly, with the furhter disadvantage of ofl contanination from backstreaming. ${ }^{6}$ Furthermore, fallure of diffusion pump cold traps would almost certainly lead 
to Irreparable contamination of vacuum walls and delicate high voltage systems, whereas cryopumping fallure only increases the partial pres sure of the pumped gases in the systen.

The high energy, high current Ion sources developed for the production of neutral beams $2 \hat{i}$ for fusion experiments require gas flows mesch in excess of the actud injected neutral Ion flux. To remove this large gas load, typically tens of Torr-1/sec, will require pumping speeds for deuterium on the order of $n 3 \times 10^{6} 11$ ters/sec for the Tokamak Fusion Test Reactor (TFTR) 3-source beamline. 5

Although large cryopums have been built ${ }^{20}$ and successfully operated, very little is known about the actual behavior of cryogenic deposits, particularly under CTR conditions. ${ }^{5}$ Benvenuti and Calder 21 , and $L e e^{22}$ have measured vapor pressures of $H_{2}$ at close to liqufd-helium temperatures. They have found that the saturated vapor pressure roughly satisfies the Claustus-Clapeyron equation

$$
\ln P_{\text {sat }}=-\frac{A}{T}+B \ln T^{\prime}+C
$$

where $A, B$ and $C$ are constants.

Though further investigations on the effects of varlous heat loads and electron bombardment were made by Benvenuit and Calder, 23 and Erents and McCracken, 24 no cryopumping assembly has been operated in proximlty of a large neutral-beam source, and in the presence of an additional intermittent temperature and possibly desorption effect ${ }^{25}$ from large bursts of neutrons and gama rays as is expected from TFTR. 


\section{Pumplng Speed Requirements for TFTR 3-Source Beamline}

Each bean line is divided into three chambers. A schematic can be found in Fig. 2. The three ion sources making up each bean line contributes a total of 90 Tor:-11ter/sec, neutralized deflected charge lons and vacuum wall desorption contributes an additional 9 Torr11ter/sec. The main requirement is oet by the pressure in chamber $2-3.84 \times 10^{-6}$ Torr.

The gas balance equations are $\mathrm{e}^{20}$

$$
\begin{aligned}
& P_{1}\left(s_{1}+c_{12}\right)-P_{2} c_{12}=Q_{1} \\
- & P_{1} c_{12}+P_{2}\left(s_{2}+c_{12}+c_{23}\right)-P_{3} C_{23}-Q_{2} \\
- & P_{2} c_{23}+\left(s_{3} \pm c_{23}\right) P_{3}=Q_{3}
\end{aligned}
$$

Solving for a relative minimum total, subject to the constraint $S_{1}=S_{2}$, we have

$$
\begin{aligned}
& s_{1}=1.71 \times 10^{6} 11 \text { ter } / \mathrm{sec} \\
& s_{2}=s_{3}=7.93 \times 10^{5} 11 \mathrm{ter} / \mathrm{sec}
\end{aligned}
$$

We can see that these high pumping speeds are not attainable with diffuston pumps. A large large assembly of titanium sublimation pump, pumping speeds of around $2 \ell / \mathrm{cm}^{2}-\sec ^{26}$, is capable of giving such a high purqing speed, but the gettering assembly would be extremely unweldy. Thus the only alternative is cryogenic pumps of total area $30 \mathrm{~m}^{2}$, assuming a pumping speed of $6 \mathrm{~T}-1 / \mathrm{sec}-\mathrm{cm} \mathrm{m}^{2}$ which can be accommodated In the neutral-beam injector volume avallable. 
II. KNOWN PROPERTIES OF HYDROGEN AND DEUTERIUM APPLICABLE TO CRYOCONDENSATION PUMPING

The properties of normal* (a) $\mathrm{H}_{2}$ and $\mathrm{D}_{2}$ at around $4.2 \mathrm{~K}$ are of great interest in cryogenic engineering, especially in the area of cryocondensation pumping. Properties of $\mathrm{nH}_{2}$ and $\mathrm{nD}_{2}$ have been tabulated extensively. 27,28 In this chaptei is a list of the triple polnts, saturated vapor pressures, and solid and liquid densities of $\mathrm{nH}_{2}$ and $\mathrm{nD}_{2}$.

\section{A. Triple Point}

Values recommended by the National Bureau of Standards 1 are IIsted below.

\begin{tabular}{ccc} 
Species & $\begin{array}{c}\text { Triple Point } \\
\text { Teiop., } \mathrm{K}\end{array}$ & $\begin{array}{c}\text { Triple Point } \\
\text { Vapor Pressure (Torr) }\end{array}$ \\
\cline { 2 - 2 } $\mathrm{nH}_{2}$ & 13.957 & 54.04 \\
$\mathrm{nD}_{2}$ & 18.71 & 128.5
\end{tabular}

The triple point of a one component system is defined when all three phases of the system are in equilibrium. From Gibbs phase rule

$$
\mathbf{v}=\mathbf{c}-\mathbf{p}+2
$$

*Hydrogen isotopes exist as a mixture of ortho and para configurations. This phenomenon is due to quantum mechanical exchange degeneracy and symmetry characteristics of the hydrogen molecular wave function. 29 The percentage of orthompara concentrations in such a oixture is temperature dependent. Para-hydrogen and orthodeuterlum predominate at cryogenic temperatures. 
where $v=$ No. of degrees of freedom

c $=$ No. of components

p No. of phases

we have, since $c=1, p=3$

$y=0$

which means that the one component system is Invariant at this particular temerature.

\section{B. Vapor Pressure}

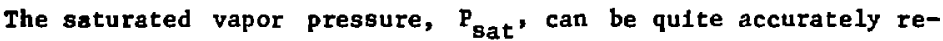
presented by the equation

$$
\ln P_{\text {sat }}=-\frac{A}{T}+B \ln T+c \text {. }
$$

down to liquid-helium temperatures.

Values of $A, B$, and $C$ are

Species

$\begin{array}{cccc} & \underline{A} & \underline{B} & \underline{C} \text { (Torr) } \\ \mathrm{nH}_{2} & 98.63 & 1.982 & 5.832 \\ \mathrm{nD}_{2} & 137.1 & 2.378 & 5.217\end{array}$

Equation 1 is defined by assuming a temperature-dependenc latent heat: of sublimation, $L$, of the form $\mathrm{m}^{30}$

$$
L=R(A+B T)
$$

where $A$ and $B$ are the constants 1isted above, and $R=8.314 \mathrm{~J} / \mathrm{mol}-\mathrm{K}$. Substituting into the Clausius-Clapeyron equation ${ }^{31}$ ylelds

$$
\frac{d \ln P \text { sat }}{d t}=+\frac{A}{T^{2}}+\frac{B}{T}
$$


$-9-$

$$
\ln P_{\text {sat }}=-\frac{A}{T}+B \ln T+C
$$

Vapor pressures below the triple point are of ten referred to as sublimation pressures.

c. Liquid and Solid Densities

Briggs et al have reviewed existing literature ${ }^{1,32-34}$ and sigBested the formulas

$$
\begin{aligned}
& P_{L}=A_{L}-B_{L} T^{2} \\
& P_{s}=A_{E}-B_{s} T^{2}
\end{aligned}
$$

and

The constants are

$\begin{array}{ccccc}\text { Species } & \mathrm{A}_{\mathrm{L}} & \underline{\mathrm{B}_{L}} & \mathrm{~A}_{\mathrm{s}} & \underline{\mathrm{B}_{s}} \\ \mathrm{nH}_{2} & 0.0412 \times 10^{6} & 0.145 & 4.43 \times 10^{4} & 0.478 \\ \mathrm{nD}_{2} & 0.0477 \times 10^{6} & 0.130 & 5.07 \times 10^{4} & 0.290\end{array}$




\section{DESCRIPTION OF A TEST CRYOPUMP FOR TFTR}

\section{A. Cryopump Construction}

Because of the diversity of conditions in the TFTR reactor environment under which future cryopumps w11l have to operate, a test prototype has been designed and constructed by the LBL/LLL joint eng1neering group. The objectives are to explore design and operations problems and limitations, to test compatibility of the cryopump in the proximity of a large neutral-beam source, and to investigate the effect of large bursts of neutrons and gamma rays similar to that expected from TFTR.

Figure 2 is a photograph of the cryopumping moduie. The primary feature of this cryopump is the black copper chevron array, consisting of $245^{\prime \prime}$ by 14" OFHC copper plates chemically blackened and bent $120^{\circ}$ vertically to provide a high-absorptivity thermal radiation shield. This was designed so that gases, mainly deuterium from the neutral-beam Ion source, will transmit through the array while providing thermal radiation Isolation for the liquid-hellum panel and cooling down the lacoming gas particles.

About 6" behino the chevron array is a double-wall quilted Btalnless-steel panel through which clrculates 11quid-helium at $4.2 \mathrm{~K}$. Th1s 11quid-helium panel provides an effective cryopumping area of 2160 $\mathrm{cm}^{2}$, to give a total pumping speed for deuterium of approximately 6.0 $1 / \mathrm{cm}^{2}$-sec. ${ }^{5}$ Unllke other crypunp designs, 35 this one does not provide an inlet reservoir for the liquid helium. Instead, the liquid helium is 
forced through the quilted envelope by 1 ts own vapor pressure, generated Instde the supply dewar through normal boiloff. The reason for this arrangement is simplicity. In fucure TFTR applications, cryopump will most probably have to be sub-cooled to below $4.2 \mathrm{~K}$ to reduce hydrogen for 1iquid-helium internal storage. Instead, liquid-hellum is simply vapor pressure. The helium circuit will be directly connected to a refrigerator through thermally isolated transfer 1ines. ${ }^{30}$ Such an arrangement is also fimportant in conserving hellum.

Immediately behind the liquid-helfum envelope, on the other face of the box facing away from the chevrons, is another double-wall stalnless-steel panel through which ctrculates IIquid-nitrogen. This panel functions as a radiation shield for the liquid-helium panel. To the sides of the liquid-helium panel are Four liquid-nitrogen ccoled OFHC copper plates. These serve to complete the thermal radiation assembly esclosing the liquid-helium panel. Thase copper panels also make up the sides of the sajopum modila and tine 24

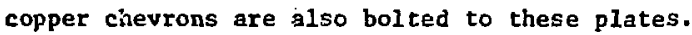

Liqufd-helium is supplied through a concentric dual bayonet fitting attached to a flexible, vacuum-jacketed liquid-helium transfer Ine manufactured by Cryolab Corp. The two-phase helium return from the cryopump is allowed to exhaust to air through a $12 \mathrm{ft}$. length of copper tubing in order to prevent upsetting the convection loop in the helium circuit. ${ }^{36}$ LIquid-nitrogen is supplied via an Armaflex insulated teflon transfer line. 
For temperature measurement, the liquid nitrogen surfaces are monitored with copper-constantan thermocouples, and the Ilquid-tieifum surfaces are provided with carbon reststors and silicon diodes supplled by Lake Shore Cryotronics. Their varfous locations are shown In FIgure 9. An electrical current of 10 microamp. was used for the reslstors and diodes. Self-heating was found to be negligible. In order to provide maximum thermal contact and to produce a unfform temperature environment the resistors and diodes were enclosed in copper hats soldered onto the 11quid-hellum surfaces. See Figure 8.

\section{B. Measuring Systems}

Static pumpingspeed measurements were made with the cryopump installed in the neutral-beam tect facility beam line (Figure 11) and with the cryopump module instde fts own vacuum enclosure (Figure 5). Dynamic pumping speed measurements were made only with the cryopump installed in the neutral-beam line, the dynamic measurements were made wth both the lon-source operating and 1dle.

Different gases, $\mathrm{H}_{2}, \mathrm{D}_{2}$ and $\mathrm{N}_{2}$, were introduced through a leak valve, the exact amount of which was monftored by a thermal conductivity type flowmeter manufactured by the Hastings-Raydist Company (Model H-50). This flowneter was callbrated against a mercury bubble leak-rate apparatus (Figure 10) in the range $1-0.5$ Torr-1iter/sec. The flowneter calibration thus obtained was found to be linear and almost Independent of the gas species. Calibration data were obtained to within an accuracy of $10 \%$ (Appendix 2). 
The pressure in the system was measured by an external glassenclosed Bayard-Alpert-type fonization-gauge (Veeco) and a nude Bayard-Alpert-type fonization gauge (Varian). The Vartan gauge was connected to a Lawrence Livermore Laboratory built fast Ion gauge power supply with a risetime of less than $1 \mathrm{msec}$. The Veeco lonfiation guage was driven by a conventional power supply. A quadrupole mass analyser (Uthe Technology International) was also used to determine the residual gas components and to measure desorption spectes during a beam pulse. The locations of the lonization gauges and the mass analyser are shown in Figure 11 .

A calibration for $\mathrm{H}_{2}, \mathrm{D}_{2}$ and $\mathrm{N}_{2}$ for the two fontzation gauges was made using a Barocel electronic manometer pressure gauge (Datametrics) which iad been callbrated against an ofl manometer in the pressure range $10^{-4}$ Torr. The Varian Ionization gauge was calibrated using both its regular power supply and the LLL-buld fast ionization gauge power supply. The results obtalned vere significantly different from the manufacturers recomended correction values. A list of the calibration results can be found in Table 7. A subsequent calibration using the same gauges on a different vacuum system yielded similar results, to within experimental uncertainties. 


\section{TEST CRYOPUMP MEASUREAENTS}

Static, dynamic and beam-desorption-effect measurements of the test cryopump were made. The pressure measuring equipment used were the calibrated Ion gauges, the LLL-built fast-response ion-gauge supply, and a quadrupole mass spectrometer (Uthe Technology International), these various instruments were all described in the last section. The measurements werc designed to find the pumping speed for $\mathrm{H}_{2}$ and $\mathrm{D}_{2}$, and to look for any desorption ef fects from a plasma beam passing approximately 36" from the condensed deuterium. Pressure measurements were made at room temperature, a correction for thermal transpiration, $(293 / 4.2)^{1 / 2}$, was not applied tr. the results since we were only interested in pumping speed measurements, not the absolute partial pressures at the surface of the condensate. The experiments were carried out both with the cryopump in its own vacuum assembly (static measurements only) and as part of the neutrallzer cell of the neutrai-beam injector Test Stand IIIA at the Lawrence Berkeley Laboratory (dynamic pumping speed and beam desorption measurements).

Before each chill-down with liquid-helium, a pressure of $1 \times 10^{-4}$ Torr was obtained either with an $L_{2}$-trapped diffusion pump (when cryopump is in its own vacuum assembly) or using the existing Test Stand IIIA vacuum. The panel was then cooled with $\mathrm{LN}_{2}$ until the thermocouples indicate a temperature at or near $77 \mathrm{~K}$, at which time Lhe cooling commenced. 


\section{A. Static Pumping Data}

These measurements were carried out both with the cryopump in 1ts own vacuum assembly, and with the cryopump installed in the beamline. $99.95 \%$ pure $\mathrm{H}_{2}$ and $\mathrm{D}_{2}$ were used. Gas flow was monitored by a callbrated Hastings flowmeter. The method used was to measure the equilibrium pressure at various gas inputs, ard then applying

$$
Q=P \times S(P)
$$

Where $Q=$ gas load

$$
\begin{aligned}
& S=\text { puwplig speed } \\
& P=\text { measured pressure } X \text { gauge correction }
\end{aligned}
$$

With the cryopump operating, a continuous gas load (leak) was admitted Into the system, metered accurately by the flowmeter for approximately 30 sec. The pressure was then noted. In this way, by varying the leak and measuring the Ufferent pressures, $p$ lot of $P$ vs. $Q$ can be obtained. A best fit slope can be obtained from this plot in the region of interest. The pumping speed can then be obtalned using Equation 1. (See Figures 12-15)

We can see from the figures that the pumping speed is alnost pressure independent in the range $1 \times 10^{-5}$ to $1 \times 10^{-4}$ Torr for deuterium, and in the range $1 \times 10^{-5}$ to $1 \times 10^{-4}$ Torr for normal hydrogen. Values of the pumping speed were:

$\begin{array}{ccc}\text { Spectes } & \text { Pumping Speed (1/sec) } \\ \mathrm{nD}_{2} & 1.43 \pm 0.15 \times 10^{4} \\ \mathrm{nH}_{2} & 1.60 \pm 0.17 \times 10^{4}\end{array}$


These values correspond to a pumping speed/unit panel area of:

$\begin{array}{cc}\text { Spertes } & \text { Pumping Speed/Unit Area }\left(1 / \mathrm{sec}_{-\mathrm{cm}}{ }^{2}\right) \\ \mathrm{nH}_{2} & 7.41 \\ \mathrm{nD}_{2} & 6.62\end{array}$

\section{B. Dynamic Pumping Speed Measurements}

These measurements were performed with the cryopump mounted adjacent to the neutralizer cell on Test Stand IIIA, and with the neutrallzer section valved off from the main sphere. The volume 1 s estimated to by 8401 . Agas pulse of about 6 toor $-1 / \mathrm{sec}$ and $700 \mathrm{mgec}$. was introduced at the plasma source position. The pressure rise of each pulse was measured by the Ion gauges. The Varian nude Ion-gauge was connected to the LLL-built fast-response lon-gauge supply (risetime = $1 \mathrm{msec}$ ). The voltage output of this fast-response supply was connected to an oscilloscope and a waveform digitizer (Quantalatch). Th1s waveform digitizer enables the pressure pluse to be recorded and read out later at various intervals. The voltage-time data can then be converted Into a pressure-tine history curve.

The pumping speed was obtained from the decay portion of the pumpdown curve.

$$
P=P_{0} e^{-\left(\frac{s}{v}\right) t}
$$

A plot on semilog paper of the pressure vs. time gave a straight IIne whose scope is 


$$
\frac{\mathrm{B}}{\mathrm{v}} \log _{10^{\circ}}
$$

where $8=$ pumping speed, and $\nabla=$ volume. (FIgures 17-18) as can be seen from thse plots, the data are a good fit to a single exponential at $P<1 \times 10^{-4}$ torr.

The dynamic pumping speeds obtained in this way were:

\section{Specteg}

$$
\begin{aligned}
& \mathrm{nH}_{2} \\
& \mathrm{nD}_{2}
\end{aligned}
$$

\section{Pumping Speed (l/sec)}

$$
\begin{aligned}
& 1.66 \pm 0.07 \times 10^{4} \\
& 1.27 \pm 0.10 \times 10^{4}
\end{aligned}
$$

\section{c. Beam Desorption Experiment}

A quadrupole mass analyser was used to monitor the rasidual gas specles concentration in the vacuun chamber at Test Stand IIIA. A hydrogen plasma beam was used for the test so as not. to confuse desorbed deuterium with those from the plasma beam. The cryopanel was loaded with deuterium, approximately 12 Torr-11ters, before the beam shots. The mass analyser output was connected to a storage oscllloscope so as to record the species concentration changes during a plasma beam pulse. A hydrogen plasma beam was then flred and recorded by the quadrupole mass spectrometer. Figure 19. We can see from the figure that mass $=4$ peak changes very little during the hydrogen beam pulse. He can conclude from this that bean desorption of adsorbed deuterium from a cryopanel is almost negligible. The fact that the mass=4 peak returned to its original amplitude almost Immediately after the plasma pulse indicates insigniftcant desorption. 


\section{NEU'RON DESORPTION AND REACTOR FLUX DIAGNOSTICS}

\section{A. Introduction}

The neutron flux generated by the $D(T, n)^{4}$ he and $D(D, n)^{3}$ He nuclear fusion reactions will react with shielding materials, vacuum containment devices, cryogenic magt.et materials and pumps, and neutral-beam Infectors. The neutron irradiations not only cause radfoactive handling problems, as in the case of the first wall and the containment vesse1, but 1 will also slowly alter the composition and the operating characteristics of certain materials, such as NbTi filaments in superconducting magnets, 37,38 and yarlous components of the neutral beam source. These changes in composition may very well be the Ifmiting factor on the duty cycle of these various crucial components, they may also be detrimental to reactor operation.

The neutral-beam fon-sources will be subject to a parti.cularly Intense neutron fiux from the reactor plasma. The injection duct and the opening In the torus (FIgure 23) for refueling would provide an aperture In the shielding of the plasma vacuum containment vessel through which neutrons and gamma radiation can escape. Most of this radiation streaming down the injection duct will emerge unattenuated, only a fraction will strike the walls of the duct and undergo scattering or varfous other reactions. The neutron spectrum for this process is shown in Figure 22.39 This source of radiation, together with the fraction transmitted through shielding, has been estimated to be at $5 \times 10^{11}$ neutrons $/ \mathrm{co}^{2}-\mathrm{sec}$ and $1 \times 10^{11}$ phorons/ $\mathrm{cm}^{2}$-sec. ${ }^{39}$ The flux of this streaming radiation at various locations can be found in Figure 24. In addition to neutrons and gammas generated 
from the plasma, streaning neutrons are also produced by the $D(d, n)^{3}$ He reactions taking place on the beam dump, and from $D(t, n)^{4}$ He reactions between tritiun atoms streaming down the injection duct and the incoming neutral deuterium beam. This additional source is expected to be quite sma11, on the order of $5 \times 10^{7}$ neutrons $/ \mathrm{cm}^{2}-\mathrm{sec}$.

The effe wo ut this source of fast streaming seutrons from the torus are many:

1. The geutral-beam Ion-source materials will be gradually be poisoned by activation products and altered through radiation damage. Thts can concetvably alter the operating characteristics of the 1on-sources.

2. Neutron and gamma heating of liquid-helfum in cryopumps, though Insignificant compared with the steady thermal radiation load, 25 would increase liquid-helium consuription and cause a higher $\mathrm{H}_{2}$ vapor pressure in the vacuum because of the tenperature Increase. 3. A more drastic effect on the cryopumps would be the desorption produced by knock-on nututrons.

Neutron damage and Increased thermal loads on cryopumps are quite well understood. Activation poisoning and neutron helium heating can be mftigated by imp roved shielding, but the desorption effect on the cryocoadensed deterium may limt the use of cryopumping to well-shielded areas away from the beam ducts, where their primary purpose is lost and thetr effectiveness decreased. 


\section{B. Berkeley Research Reactor Exper1ment}

In order to ascertain the effect of fast neutrons and gamma radiation on the absorbed deuterfum gas wolecules, an experiment has been planned by the LBL CTR-staff to Irradiate the deuterlum-loaded cryopanel assembly - at the Berkeley Research Reactor. It is hoped that results obtained from this experiment will provide data and information on how a cryopanel w111 respond to an actual radiation load.

Heutron Induced radiation damage on solids has been studied extenalvely. 40,41 It is reasonable to expect that neutrons will also interact with the amorphous condensed gases as they do with atoms In a solid. The primary knock-on deuterium molecules produced from neutron-deuteron coll1sions will mfgrate and break more adsorption bonds, creating what is comparable to a collision cascade In radiation damage. Ihts may lead to release from the condensation surface, lowering pumping speeds and raising the vapor pressure of the varfous gases, particular deuter 1 ut In the vacuum. This effect, if allowed to happen on a large scale, would serfously undermine the ef fectiveness and appeal of cryocondensation pumping--mainly its high pumping speed. If experiments were to prove that neutron knock-on collisions do give large desorption effects, current TFTR reactor designs, especially those for the neutral-beam infection systems, 19 will have to be revised to include more shlelding and to locate the cryopumps in areas with the lowest neutron flux.

The Berkeley Research Reactor (BRR) (Figure 20) produces an Intense pulse of neutrons and gamma rays in a Gaussian pulse with a half width of about $12.6 \mathrm{msec}$. Pulses are generated by pneumatically ejecting a control rod from the reactor core and placing it in a prompt-critical 
condition, up to $\$ 3.00$ above delayed critical. The resultant power excursion is terminated due to the large negative temperature coefficlent of reactivity of the uranium-zirconium fuel-moderator assembly. The result of this power excursion is a $12 . \dot{6} \mathrm{msec}-\mathrm{halfw}$ idth neutron and gamma pulse with an Integral power of approximately $16.3 \mathrm{MW}-\mathrm{sec}$. Data ${ }^{42}$ from previously measurad reactor pulses are given In Figure 21, as measured in the Exposure Room. Figure 22 is a plot of the spectrum of a BRR neutron pulse, assuming negligible degradation by the moderator. Also in the Figure are the expected TFTR streaning and transmitted neutron spectrum. Although the BRR fast neutron pulse has a fast neutron fluence of $0.72 \times 10^{11}$ neutrons/cm ${ }^{2}$-pulse, which is comparable to what is expected from TFTR-1.16 $10^{11}$ neutrons $/ \mathrm{cm}^{2}-$ pulse, the BRR spectrum is much richer in thermal neutrons which could be eliminated by borated polyethylene blocks and lead sheets in the actual experiment. The measured gamma dose of the BRR at 2 feet from the core in the Exposure Room region corresponds to a gama flux of $1.74 \times 10^{13}$ photons/ $\mathrm{cm}^{2}$ -pulse, assuming a gamma spectrum corresponding to that from promt fission. It can also be seen that the reactor fast neutron spectrum is much sof ter (has more 1ower-energy particies) than the one expected from TETR.

\section{Reactor Pulse Measurements}

Accurate measurements of the neutron spectrum and the gamma flux of a $\$ 3$ pulse were made in order to ascertai $i_{\vec{n}}$ the neutron spectrum in which the cryopum w1ll be exposed. Measurements were only made in the Exposure Room Factlity of the Berkeley Research 
Reactor. The method used was the activation of cadolum covered ${ }^{197} \mathrm{Au}$

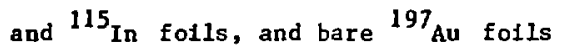

from a threshold--detection packet foll (Reactor Experiments, Inc.),

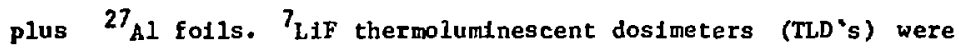
used to measure the total gamma flux. Table 25 contains a Ifst of the foll materials, activation reactions, products, cross-sections used for calculations, and threshold energles. The cross-section values were taken from Calamand. 43

The threshold folls were carefully weighed and enclosed in a plastic vial, approximately $1^{\prime \prime}$ In diameter which was then placed 24" from the reactor core Indentation in the Exposure Room Facility and subjected to a $\$ 3$ pulse. The folls were then retrieved and the photopeaks counted in a calibrated NaI(TI) single-channel scint1lation counter (Figure 26). This assembly uses two NaI(T1) crystals placed facing each other in order to Improve the counting efficlency. The product nuclides counted were as follows:

Sample Reaction Product t1/2 Peak (MeV) Counted Eeff(MeV)

$\begin{array}{lccccc}27 \mathrm{~A} 1 & (n, p) & { }^{27} \mathrm{MB} & 9.5 & 1.013 & 3.3 \\ 27_{\mathrm{A} 1} & (n, \alpha) & 2{ }_{\mathrm{Na}} & 15 \mathrm{hr} & 1.37 & 8.7 \\ 115_{\mathrm{In}(\mathrm{Cd})} & \left(n, \mathrm{n}^{\circ}\right) & 115 \mathrm{~m}_{\mathrm{In}} & 4.5 \mathrm{hr} & 0.335 & 1.0\end{array}$

Gamma rays produced scintillations were amplified successively by the photomltiplier and the linear amplifiers. The amplified signals were then fed into the single channel analyser and an oscilloscope where the gama energy spectrum was displayed. The single channel analyser window was then narrowed on to the gamma peak 
we were interested in so that only counts due to that particular peakw111 be registered. Both NaI(TI) scintillation counters were set this way. Counts were then taken with two timer controlled scalars.

A correction factor,

$$
e^{+\lambda t}
$$

was used to correct for decoy between activation product nuclide production and the time of counting.

An abundance ratio,

$$
\frac{1}{r^{-r a y} \text { abundance }}
$$

was also used to correct for less than $100 \%$ gamma ray abundance in the decay spectrum.

A final correction factor, $C_{s c}$, was used to correct for counter efficiency. Since not all the gamas produced by the radionuclides are counted by the scintillation counter, a calibration curve was made using various calfbrated sources to produce a rpm/cpm(Csc) vs gamma ray energy curve.

Hence, for the NaI(T1) sintillation counted nuclides, the activity at the time of the pulse, In disintegrations per minute, is given by

$$
A_{0}=(\mathrm{cpm}) \times \mathrm{e}^{+\lambda t} \times \frac{1}{r^{-\mathrm{ray} \text { abundance }}} \times c_{\mathrm{sc}}
$$

where cpm-number of counts per minute at the time of counting The ${ }^{197}$ Au and cadmium-covered 197 Au folls were also counted in a colncidence spectrometer (Figure 27), and the resuits comared well with those from the scintillation detectors. The product nuclides 
counted were:

\begin{tabular}{|c|c|c|c|c|c|c|}
\hline Sample & Reaction & Product & $t 1 / 2$ & $\begin{array}{c}(\mathrm{MeV}) \\
B-y \text { energy }\end{array}$ & $\begin{array}{l}\text { y-energy } \\
\text { abundance. }\end{array}$ & (b) \\
\hline${ }^{197} \mathrm{Au}$ & $(n, Y)$ & ${ }^{198} \mathrm{Au}$ & $2.7 d$ & $\begin{array}{c}0.412 \text {, no } B \text { energy } \\
\text { discrimination }\end{array}$ & 957 & 86.88 \\
\hline${ }^{197}$ AutCd & $(n, \gamma)$ & ${ }^{198} \mathrm{Au}$ & $2.7 d$ & same as above & $95 z$ & 86.88 \\
\hline
\end{tabular}

In the colncidence method, counts were taken with the and channe1s in coincidence with each other, both background and folls were counted this way. Then leaving the foll in place, counts were taken with the $B$ and $\gamma$ channels out-of-coincidence in order to measure the accidental coincidence effect. The source strength at the time of counting can then be found by

$$
\operatorname{cpm}=\frac{(B)(\gamma)}{(B \gamma)} \quad \text { (cpm) }
$$

where $(\beta)$ number of beta particles with analysers in colncidence (background corrected)

$(\gamma)=$ number of gammas with analysers in coincldence

(background corrected)

$(B Y)=$ number of coincident counts with channels in colcidence - number of coincidence (background corrected)

The abundance correction is $1 / 0.95$. The decay correction was taken to be $e^{\lambda t}$, where $t$ is the elapsed time between the reactor pulse and the time of counting.

The activity of the gold folls then is given by 


$$
A_{0}=(c p m) \times \frac{1}{0.95} \times e^{+\lambda 198 A u^{t}}
$$

The activity difference between the Cd-covered and the bare Au foils represents the contribution of the thermal flux, corresponding to the $86.88 \mathrm{~b}$ cross section.

To calculate the fluence of the reactor pulse, we assume the pulse to be a delta function, producing $n \sigma$ product nuclides instantaneously at the time of irradiation. We have

$$
\begin{aligned}
& \frac{d N}{d t}=n \sigma \phi-\lambda N \\
& N=\frac{n \sigma \Phi}{\lambda}\left(1-e^{-t_{1}} 1\right)=n_{\sigma \phi t_{1}}
\end{aligned}
$$

where $t_{1}=$ reactor pulse duration.

From $N=n_{1} \phi t_{1}$

we have

$$
\begin{aligned}
A_{0} & =\lambda N=n \lambda \sigma \phi t_{1} \\
\phi t_{1} & =\frac{A_{0}}{n \sigma \lambda}=\frac{A_{0} t_{1 / 2}}{n \sigma(0.693)}
\end{aligned}
$$

where $\quad s t_{1}=$ fluence of the $\$ 3$ reactor pulse

$$
\begin{aligned}
& \Lambda_{0}=\text { dpm of product nuclide at time of pulse } \\
& \sigma=\text { cross section of the particular activation } \\
& \text { reaction } \\
& \eta=\text { the number of atoms in the foll }
\end{aligned}
$$


with $\varepsilon$ at inlc abundance of isotope being irradiated

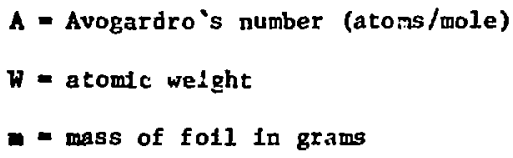

The TID's were read on a Harshaw TLD readout unit. A cal1bration using similar $7_{\text {LIF }}$ TLD's was made at the ${ }^{60}$ Co irradiation facility at the Lawrence Berkeley Laboratory in our range of Interest. Figure 28 Is a graph of this calibration. Gamma dose readouts from the reactor pulse were read directly from this callbration curve.

Using this method, the neutron spectrum and the Integrated gama dose of a $\$ 3$ reactor pulse was measured. The results are shown in F1gure 29.

The $>8.7 \mathrm{MeV}$ fluence shows a large deviation from what is expected, that $1 \mathrm{~s},<1.1 \times 10^{12}$ neutrons $/ \mathrm{cm}^{2}$, because of the lack of correction for the continuous Compton peak of the $2.75 \mathrm{MeV}$ gamma peak of ${ }^{24} \mathrm{Na}$. The counting error was estimated using

$$
\Delta S=\frac{S+2 B}{S}(100)
$$

$S=$ counting rate (background corrected)

B = background counts 


\section{Conclusion}

A cryocondensation pumping design has been proved to be practical both in operation and in meeting pumping speed requirenents called for In fusion reactor experiments. Varlous instrumentation for this application have been evaluated and tested for measurements and diagnostics. Beam Interaction with the absorbed deuterium has been found to be minimal. $A$ method has also been developed whereby the neutron spectrum and gamma dose which will be used for a future knock-on desorption experiment can be evaluated. 


\section{APPENDIX I}

$0.5 \mathrm{~W}$ Allen-Bradley resistors were used for monitoring low temperatures. These were calibrated by immersion in IN $_{2}$, WHe, room temperature and an lce bath. The resulting data were fitted to an empirical formula given be clenment 44

$$
\ln R+\frac{K}{\ln R}=A+B / T .
$$

A computer program was written to rit the above constants to the experimentai data. A list of the resistance vs. temperature wes obtained.

The silicon diodes were calibrated by the menufacturer. A plot of one of the calibrations is included. 


\section{APPENDIX II}

The Hastings flowmeter was calibrated against a mercury leak apparatus as show in Figure 10. The time needed for the mercury bubble to traverse the $1 \mathrm{~cm}^{3}$ volume tube was recorded by a stop clock. The pressure difference between the beginning and the end of the run and the reading on the Hastings flowneter were noted. The results of this calibration for $D_{2}$ and $H_{2}$ are included in Figures 32 and 33. 


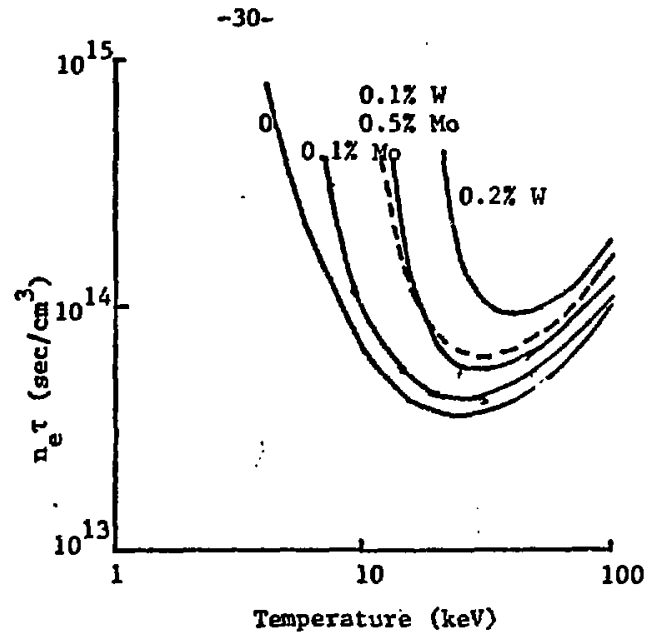

Lawson condition for a D-T reactor with various high 2 impurities

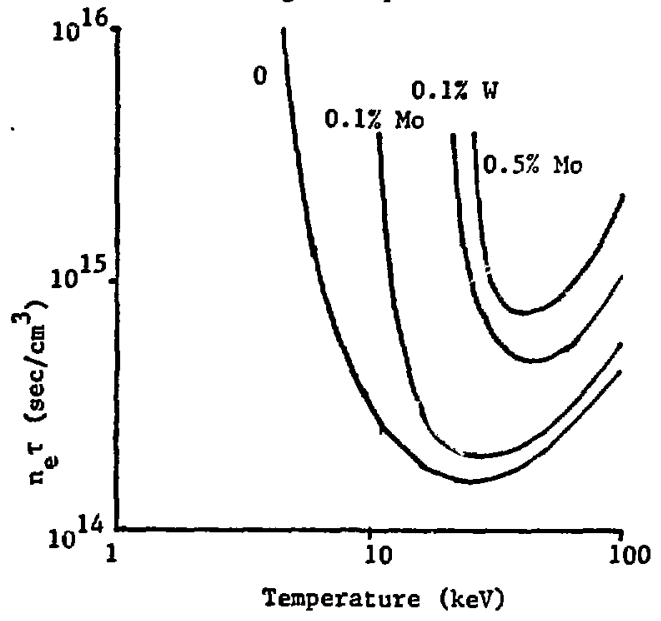

Ignition condition for a D-T reactor with vaxious high $\mathrm{Z}$ impurfties

Fig.1 EFEECT OF HIGH $Z$ IMPURITIES ON THE IGNITION AND LAWSON CONDITIONS 


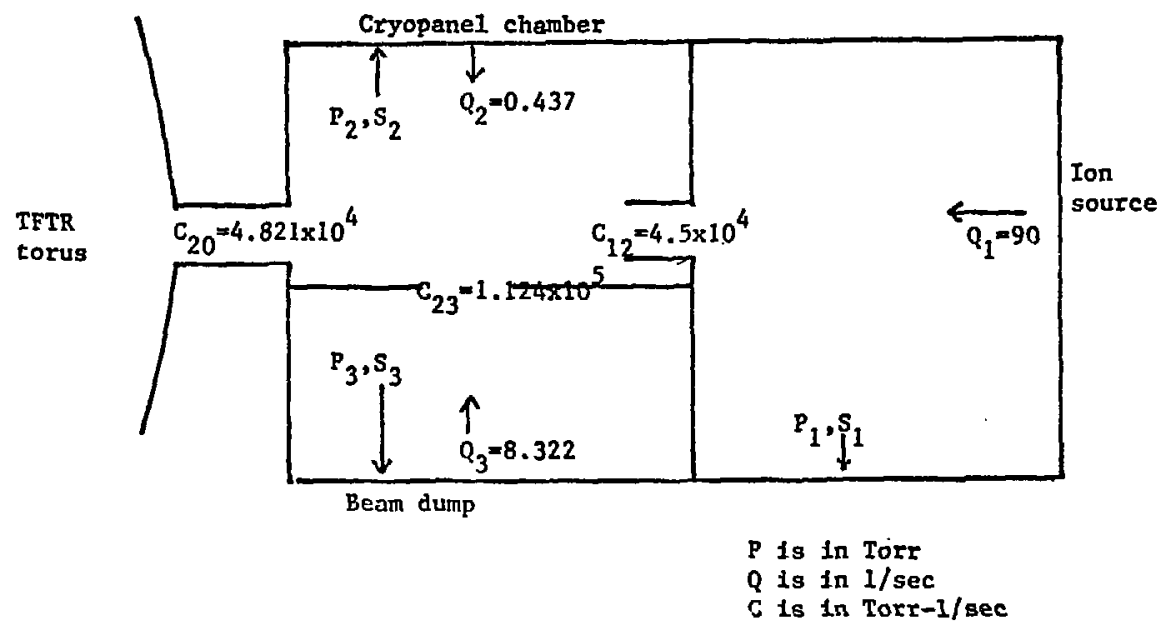

Fig. 2 SCHEMATIC OF NEUTRAL BEAM INJECTION UNIT SHOWING VARIOUS GAS LONDS AND CONDUCTANCES 


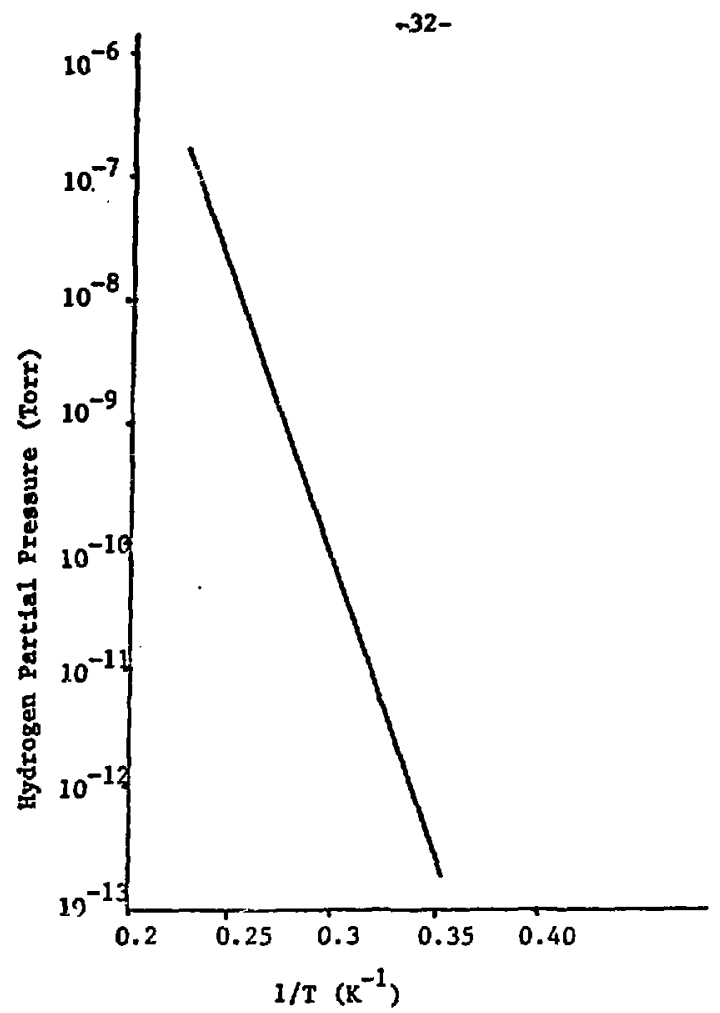

Fig. 3 SATURATED VAPOR PRESSURE VS. TEMPERATURE FOR HYDROGEN 
$-33-$

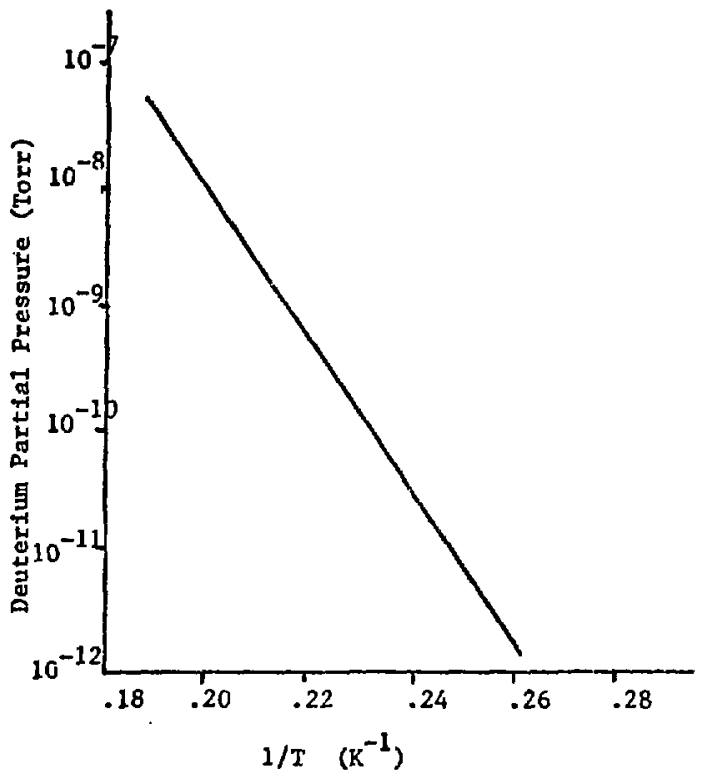

Fig. 4 SATURATED VAPOR PPESSURE VS. TEMPERATURE FOR DEUTERIUM 


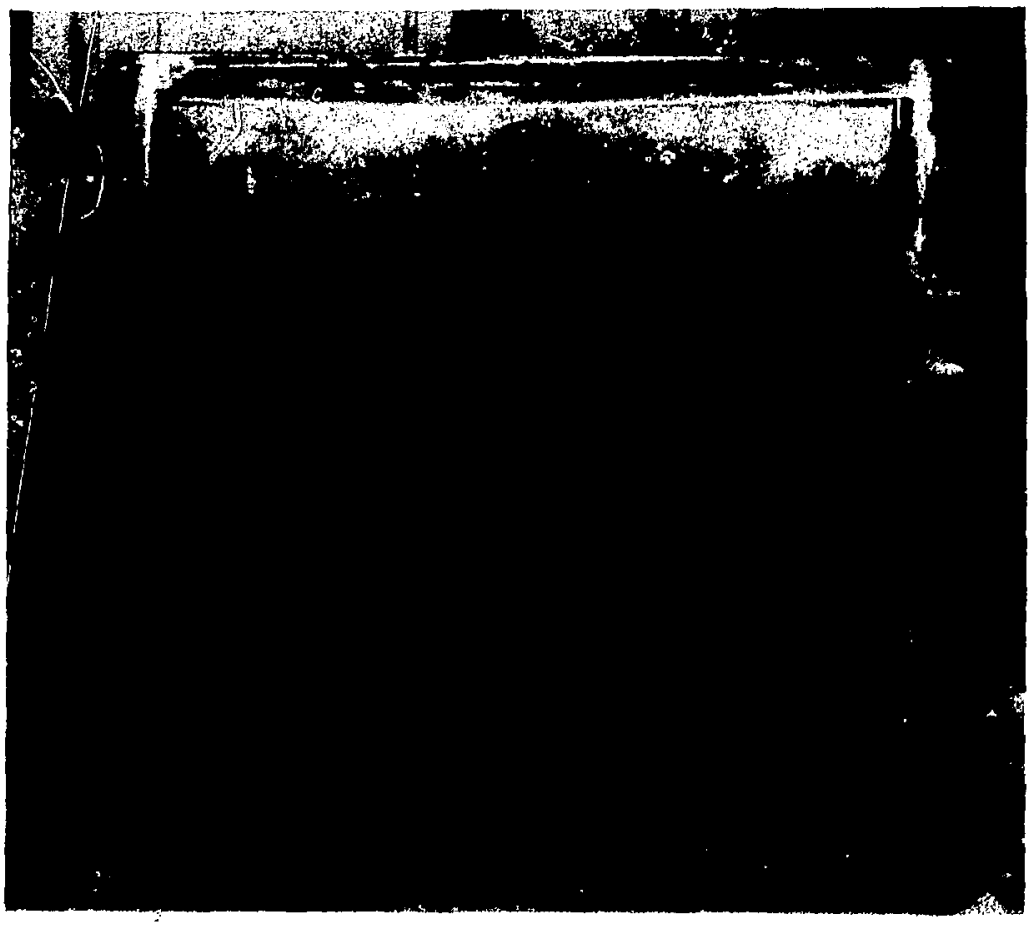

CBB 774-3650

Fig. 5 


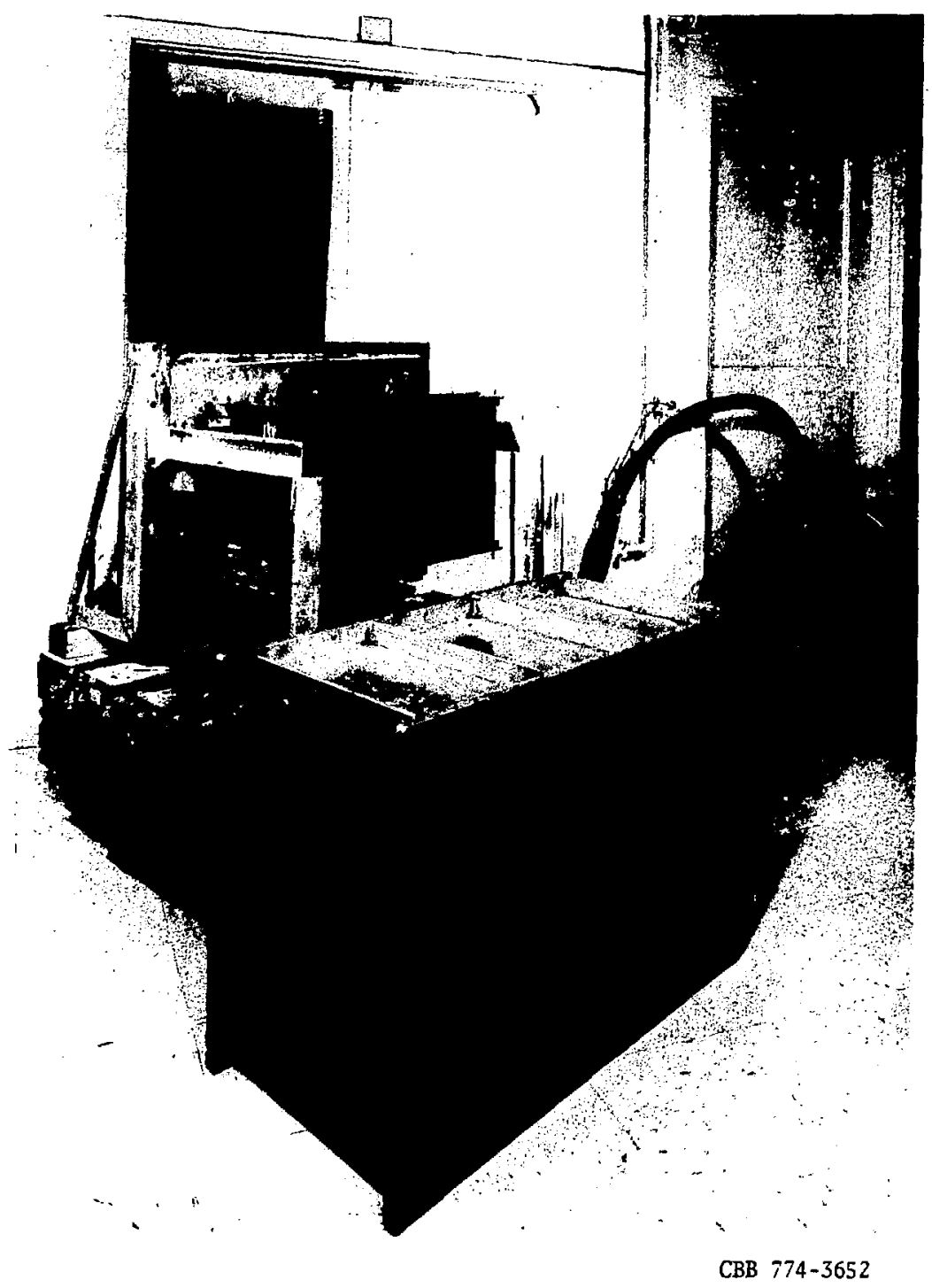

Fig, 6 
Gas Species

$$
\begin{aligned}
& \mathrm{D}_{2} \\
& \mathrm{H}_{2} \\
& \mathrm{~N}_{2}
\end{aligned}
$$

Outside B-A Gauge

$$
3.56 \pm 0.07
$$

$3.36 \pm 0.27$

$1.54+0.06$
Nude B-A Gauge

$$
4.01 \pm 0.24
$$

$3.74 \pm 0.11$

$1.70 \pm 0.03$

BAYARD-ALPERT IONIZATION GAUGE CALIBRATION FACTORS

Fig. 7 


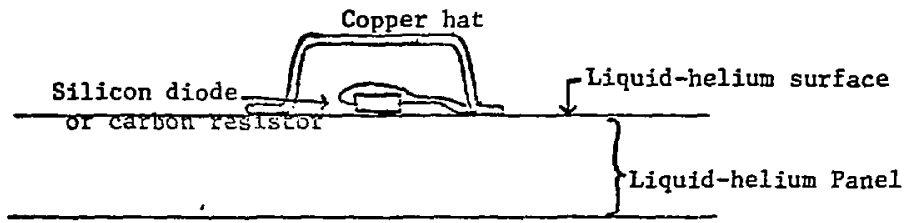

COPPER-HAT ENCLOSLRE FOR SILICON DIODE OR CARBON RESISTOR

Fig. 8 


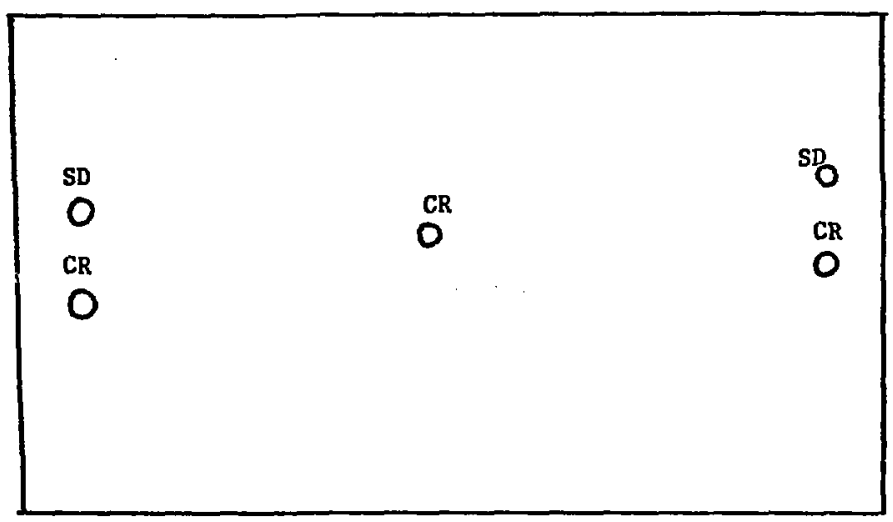

Back of stainless steel LHe panel

LN, back pane1

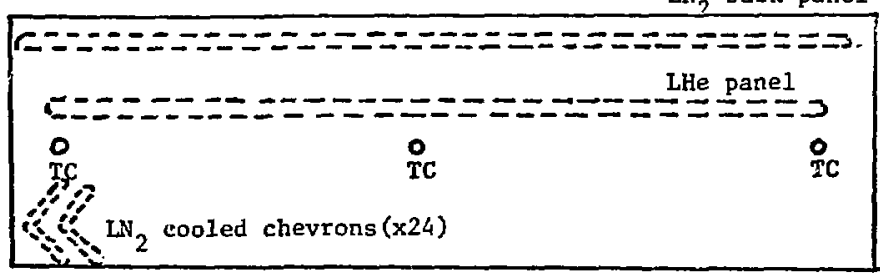

Top of cryopump assembly

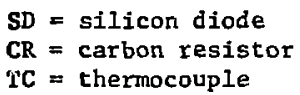

LOCATION DF VARIOUS TEPPERATURE DIAGNOSTICS

Fig. 9 


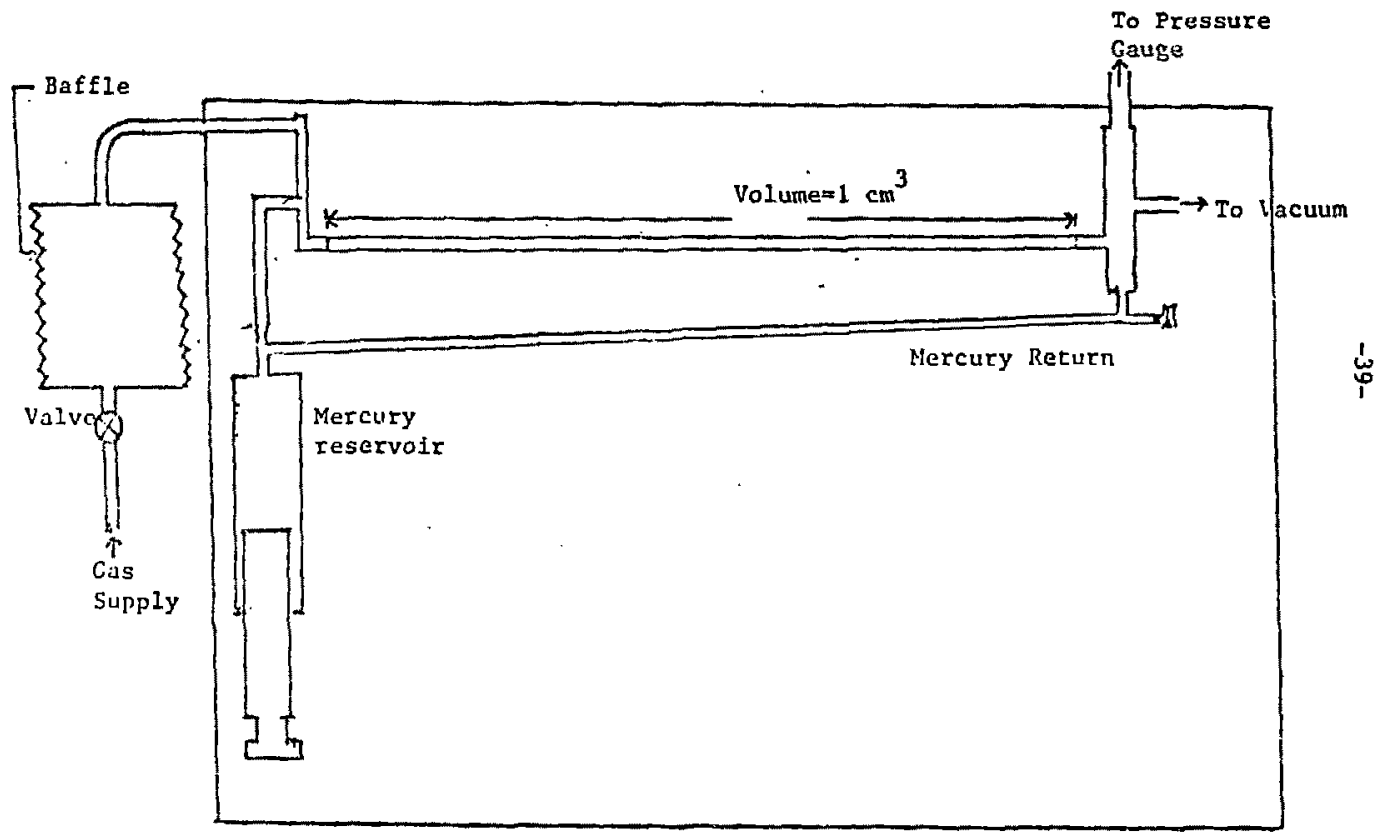

Fig, 10 MERCURY BUBBLE LENK FLOMMETER 


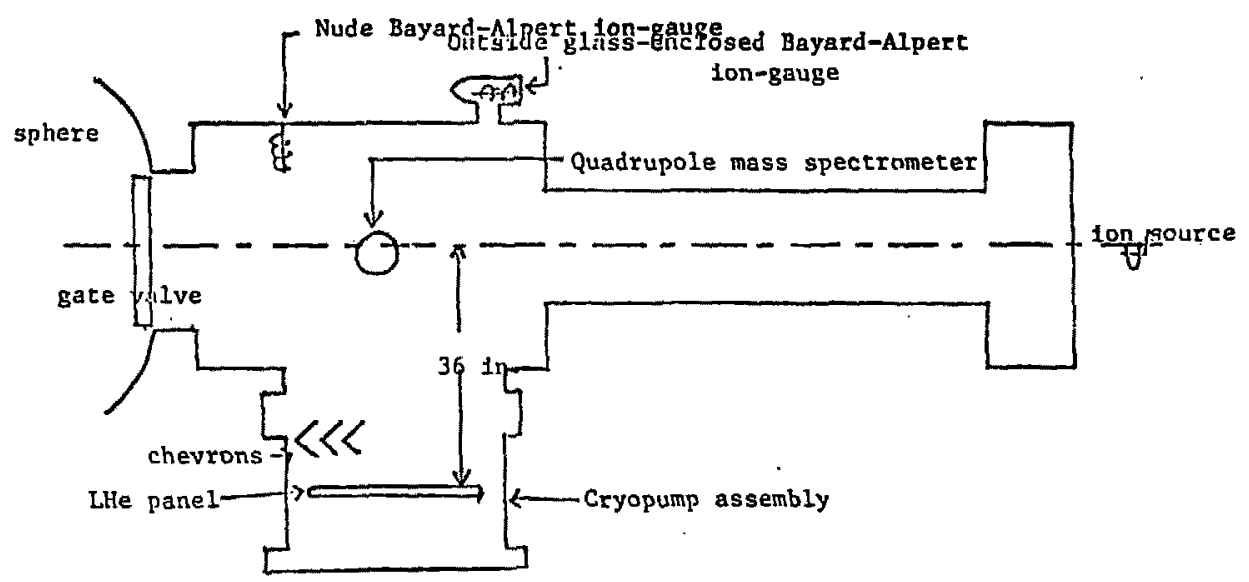

(Top view)

LOCATION OF CRYOPUMPING ASSEMBLY IN NEUTRAL BEAM TES'L FACILI'TY IIIA BEMMLINE

Fig * 11 


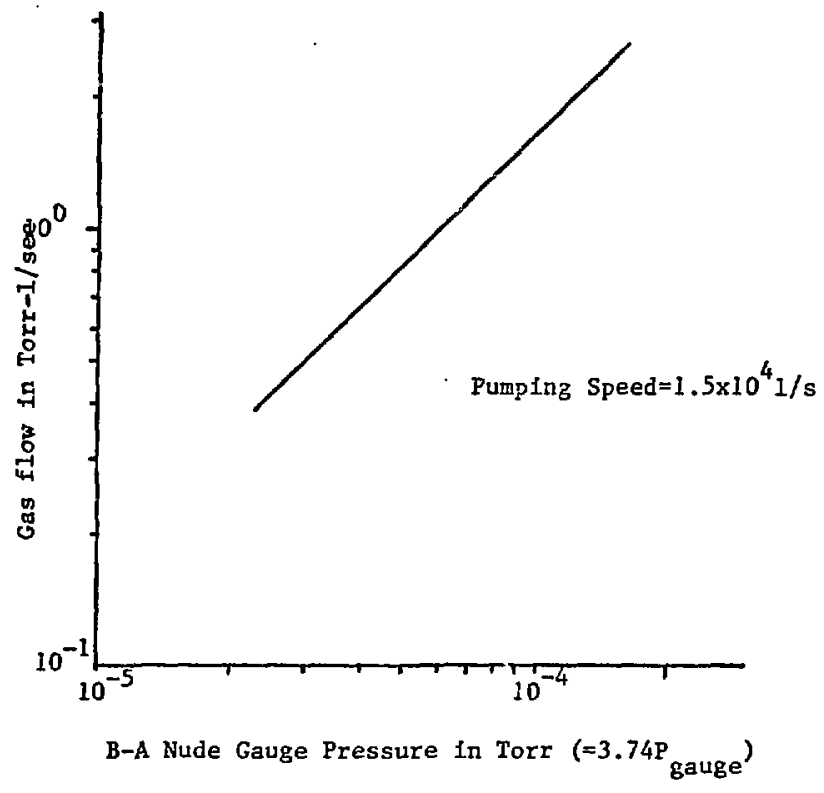

PUMPING SPEED FOR HYDROGEN

Fig. 12 


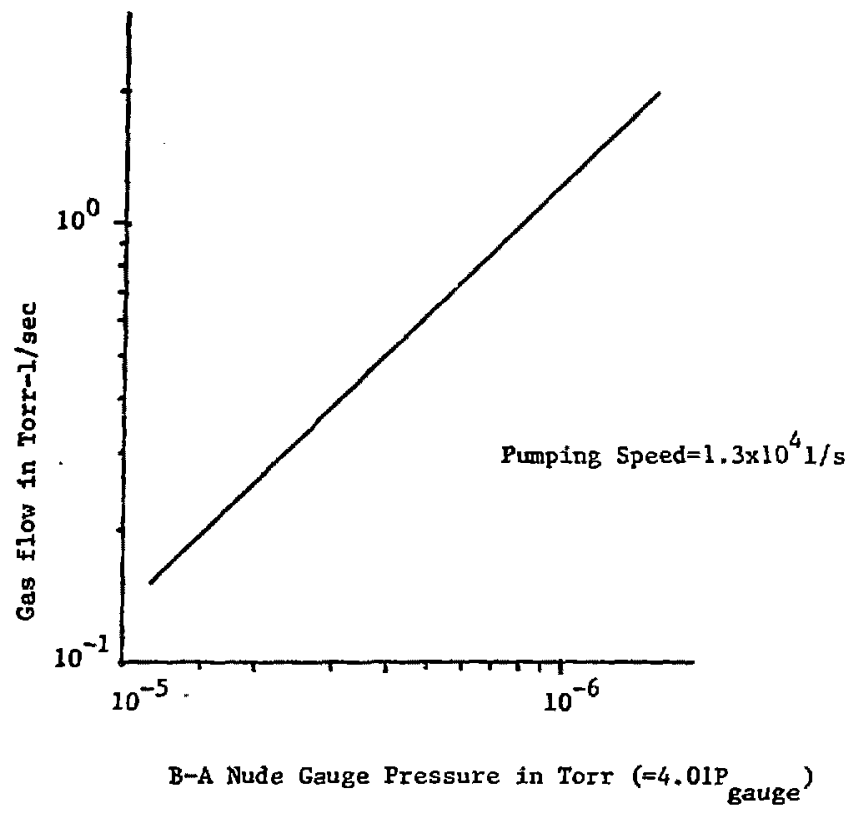

PUIPING SPEED FOR DEUTERIUM

Fig. 13 


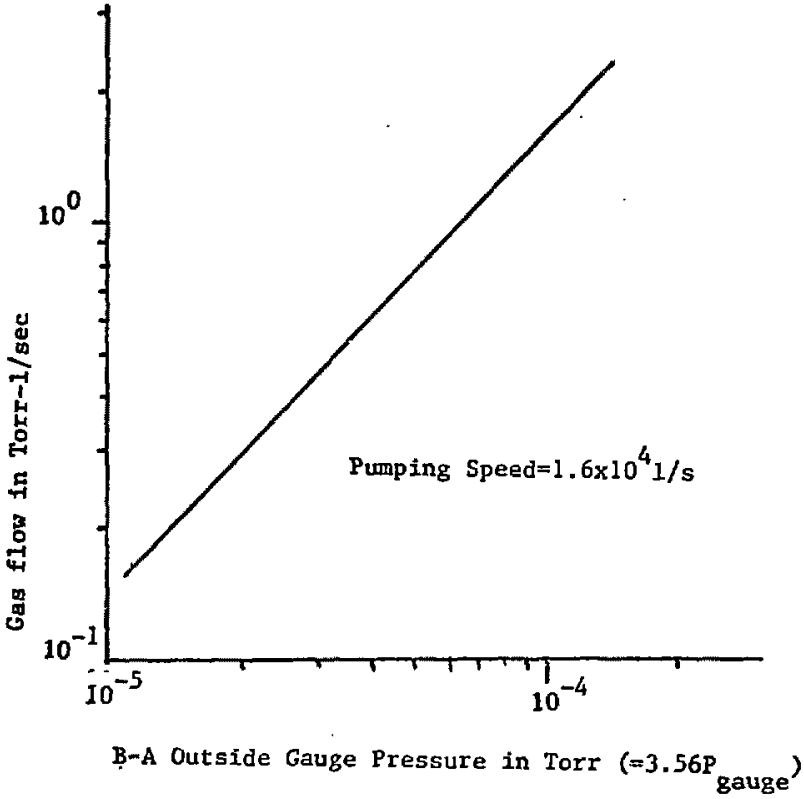

PUAPING SPEED FOR DEUTERIUM

Fig. 14 


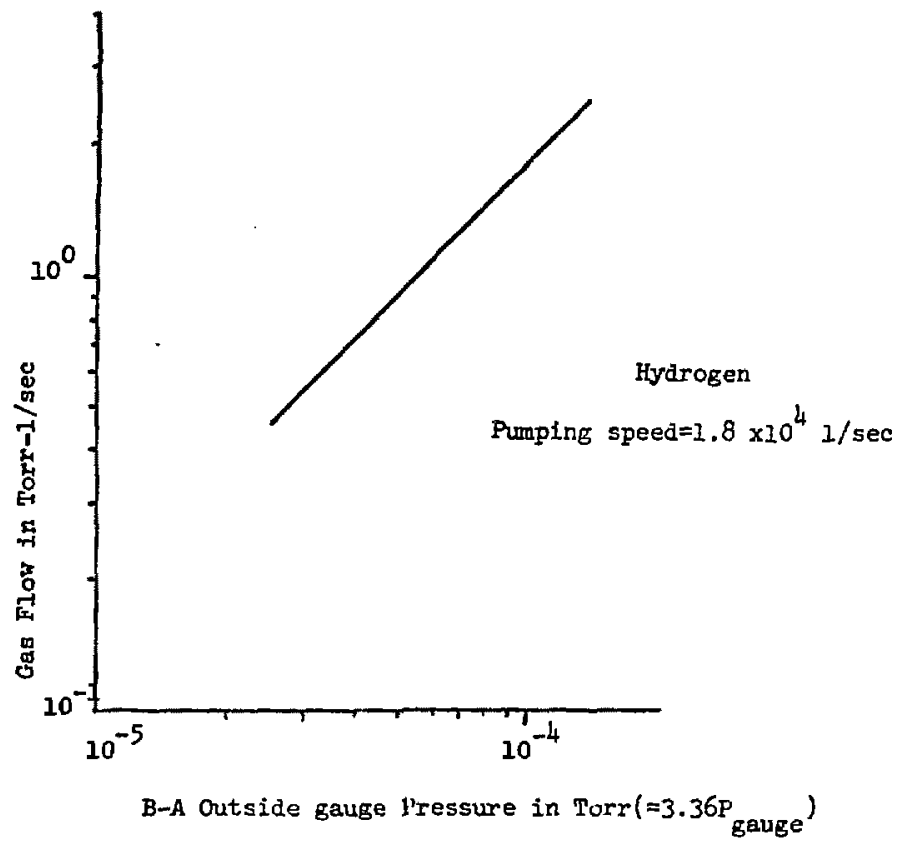

PUMP TIG SPEED FOR HYDROGEN

Fig. 15 


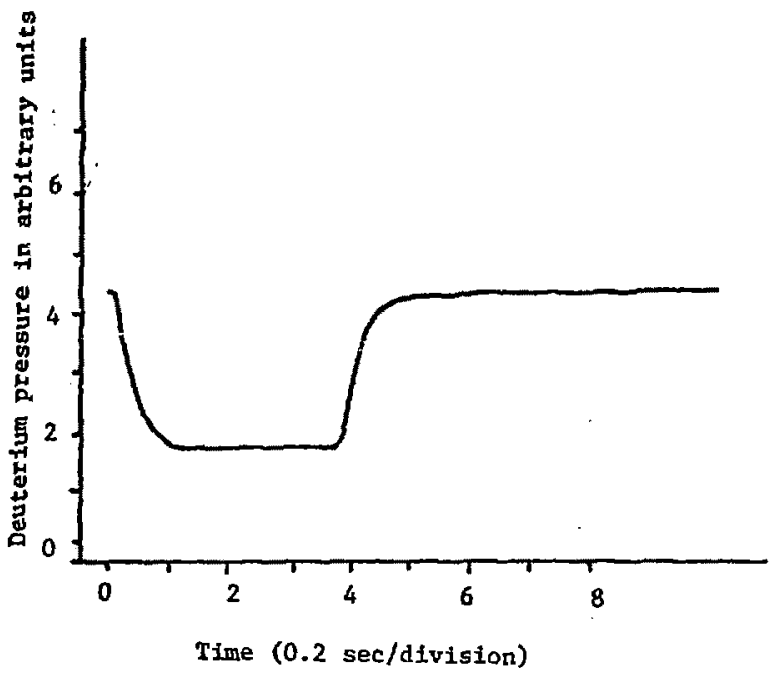

DEUTERIUM ION-SOURCE PULSE, BEAMLINE OPEN TO SPHERE

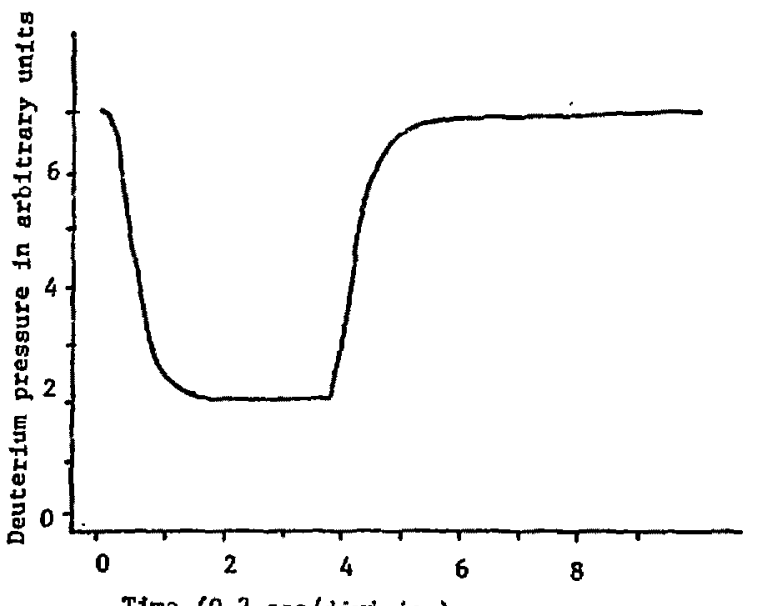

Time $(0.2 \mathrm{sec} /$ division $)$

DEUTERIUN IOH-SOURCE PULSE, BEAMLINE CLOSED TO SPHERE RRESSURE IISTORY CURUSS USED FOR MEASUREING DYNAMIC PUMPINC SPEEDS 


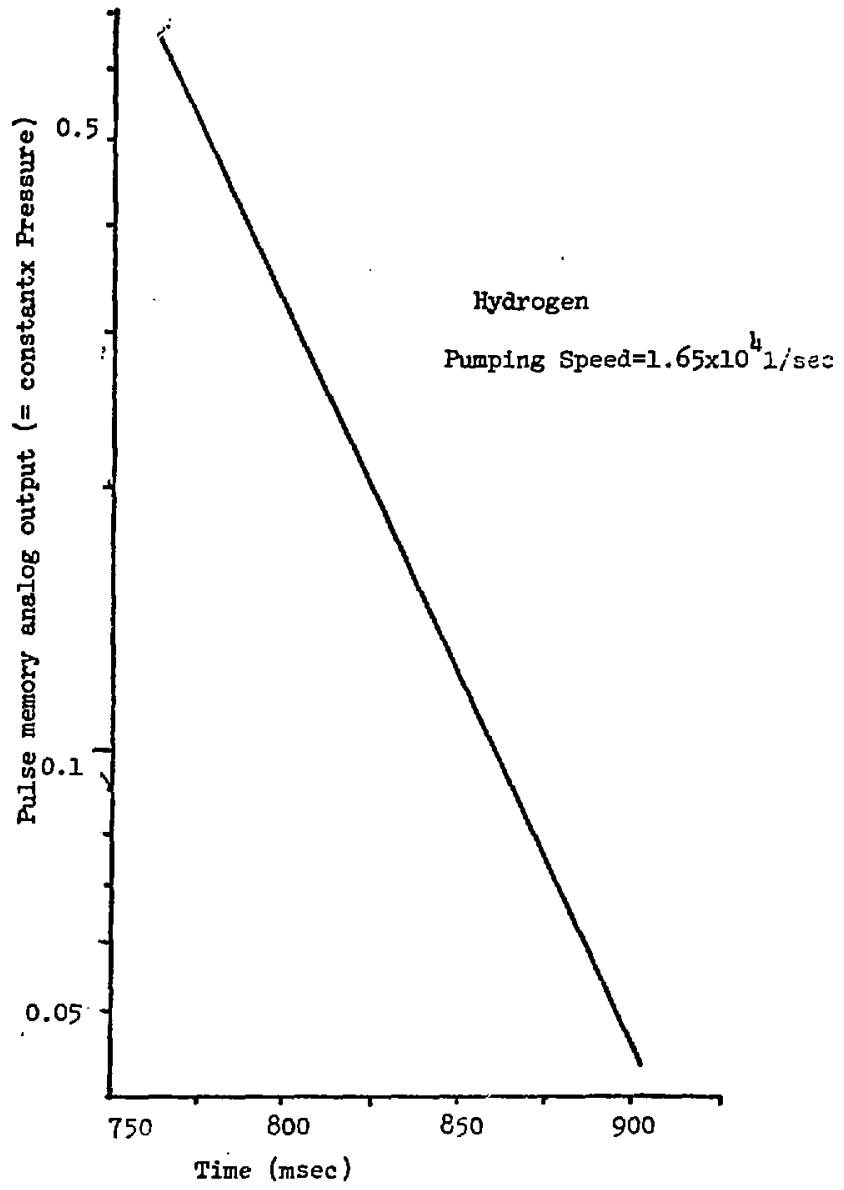

DYNAMIC PUSPIIT SPEED ILEASUREMENT FOR HYDROGES

Fig. 17 


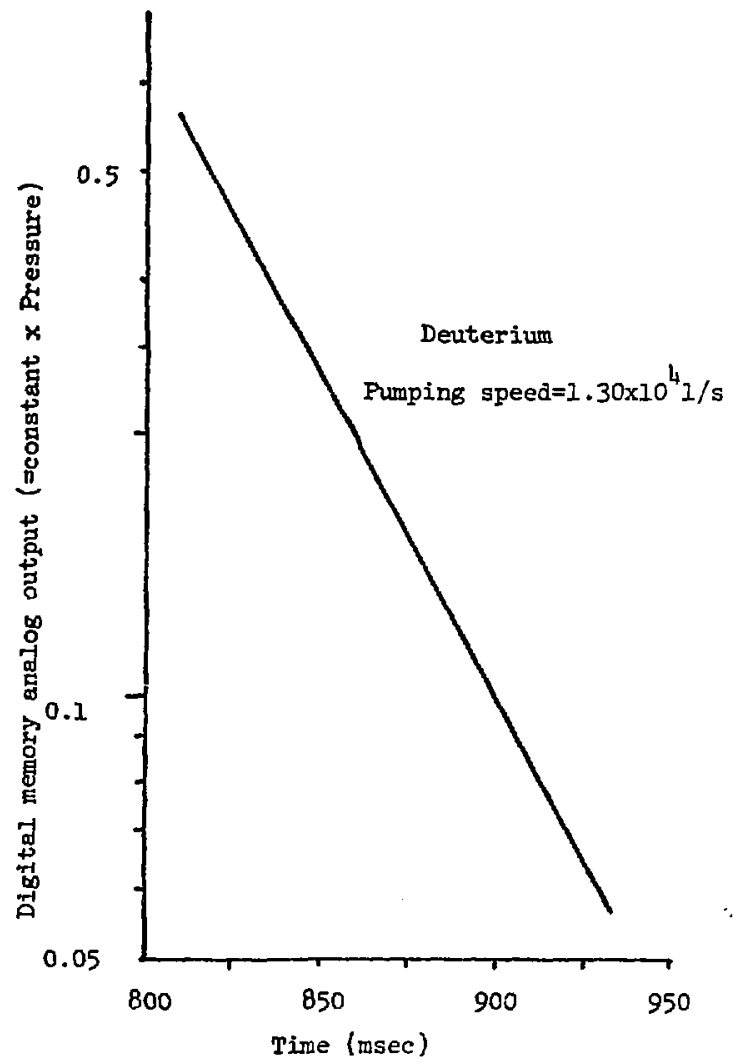

DYNAMIC PUIRING SPEED MEASUREMENT FOR DEUTERIUM Fig. 18 

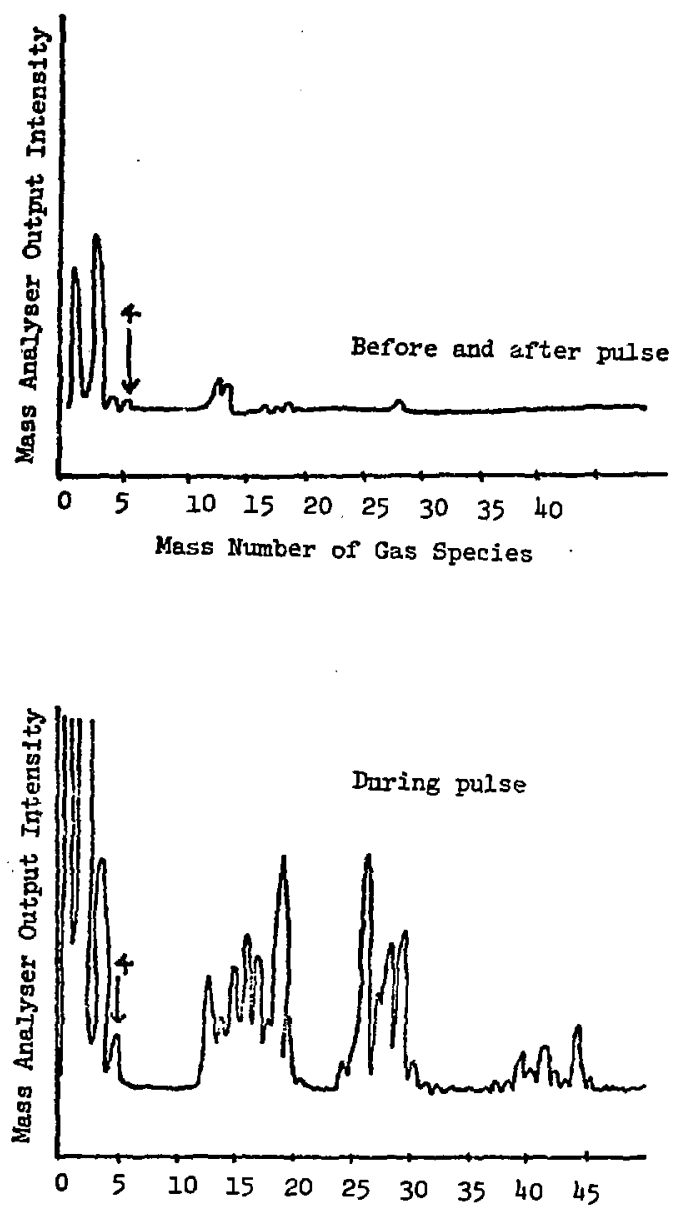

Mass Number of Gas Species

Mass Analyser Output of a Hydrogen-gas operated Ion-source and Deuteriur-gas Loaded Cryopanel 


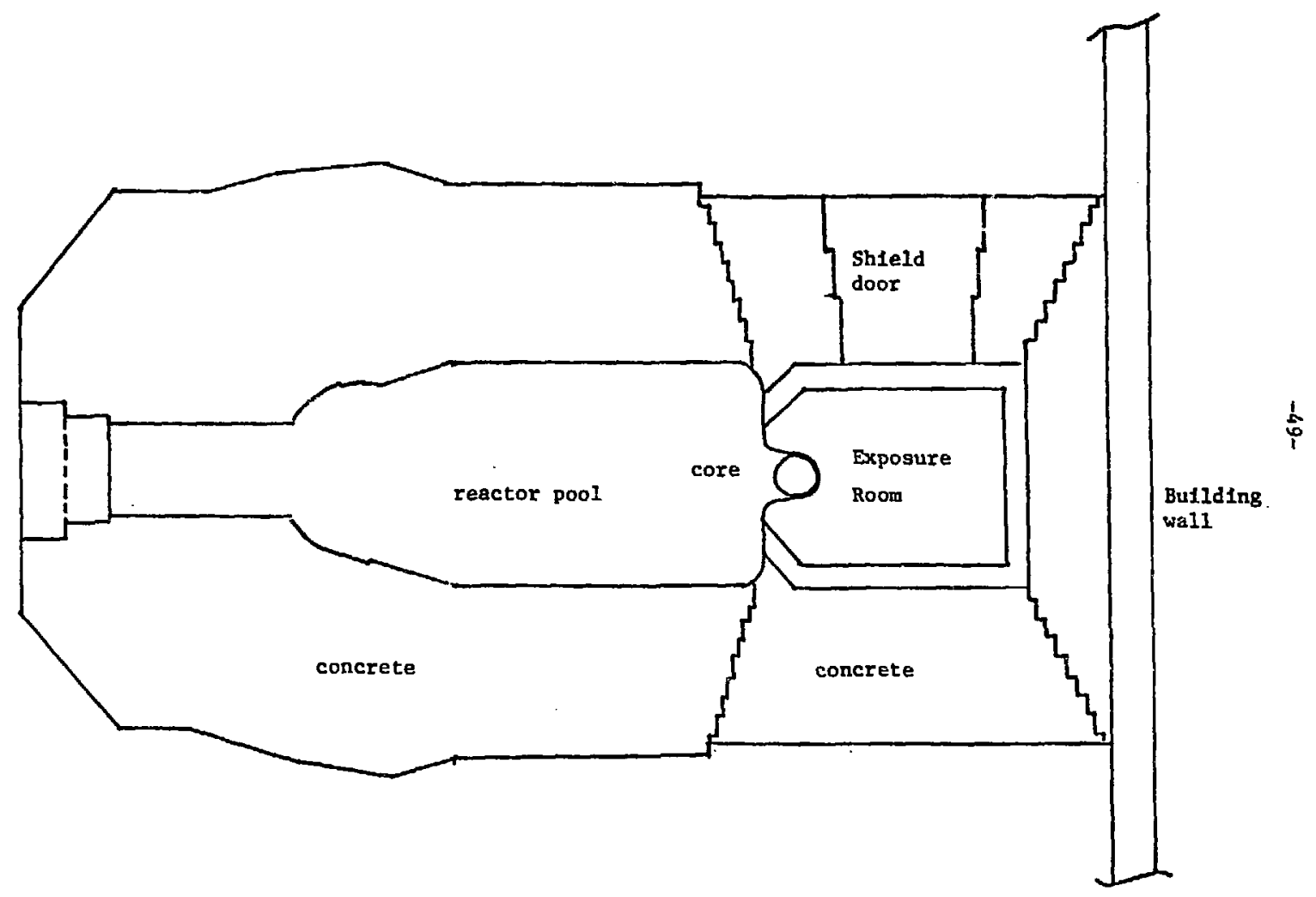

Fig. 20 TOP VIEW OF TUE BERKELEY RESEARCH REACTOR 


\begin{tabular}{|c|c|c|}
\hline $\begin{array}{l}\text { Distance From } \\
\text { Core in. }\end{array}$ & $\begin{array}{l}\text { Thermal Neutron } \\
\text { Fluence } \mathrm{n} / \mathrm{cm}^{2}\end{array}$ & $\begin{array}{l}3.0 \mathrm{MeV} \\
\text { Neutron Fluence } \mathrm{n} / \mathrm{cm}^{2}\end{array}$ \\
\hline 24 & $7.67 \times 10^{11}$ & $13.8 \times 10^{11}$ \\
\hline 36 & $4.37 \times 10^{11}$ & $5.86 \times 10^{11}$ \\
\hline 48 & $2.69 \times 10^{12}$ & $3.15 \times 10^{11}$ \\
\hline
\end{tabular}

BERKELEY RESESFCH REACTOR INTEGRATED NEUTRON

FLUENCE

Fig. 21 


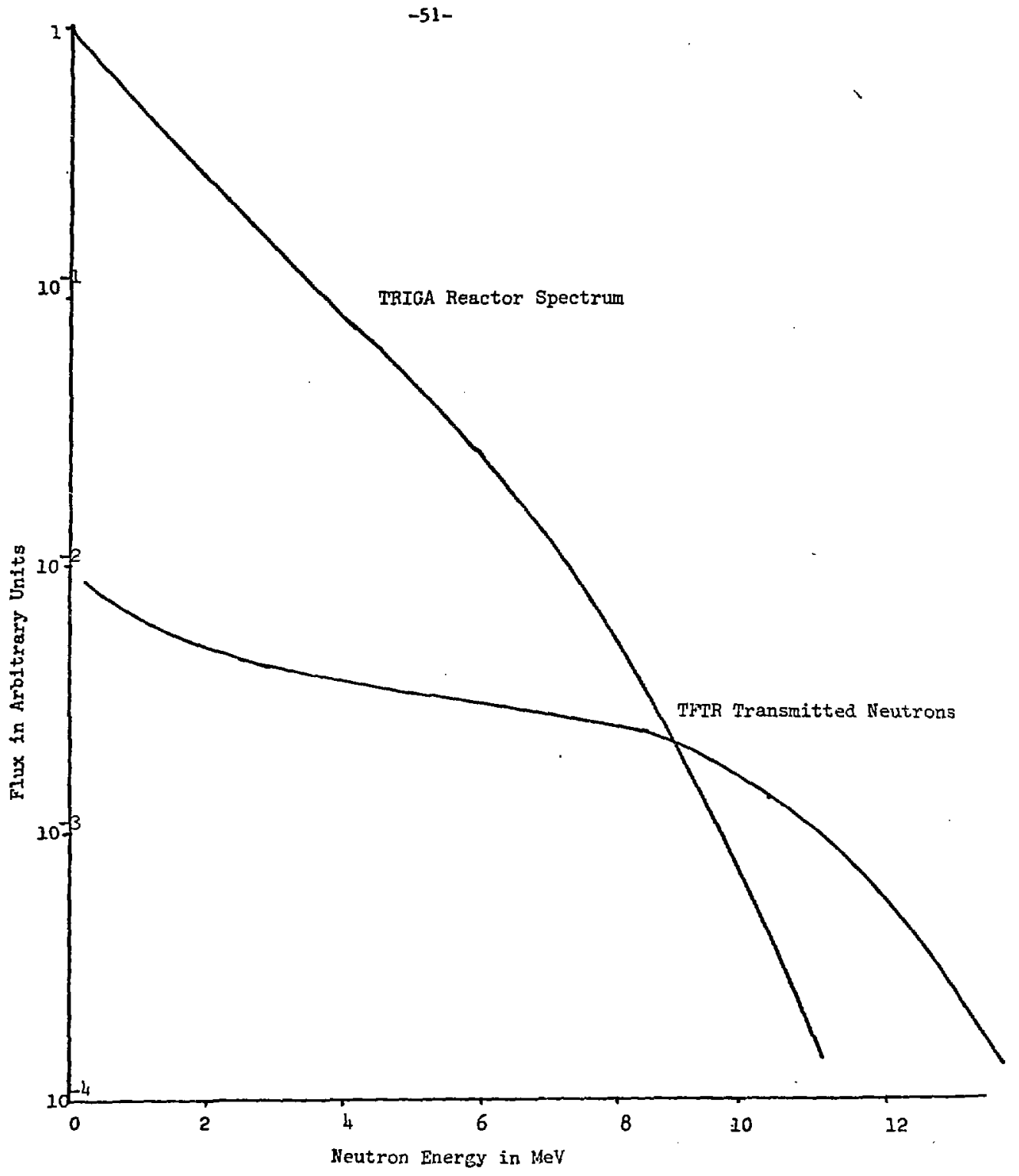

COMPARISON BETHEEI TFTR AND TRICA NEUTRON SPECTRUM

Fig. 22 


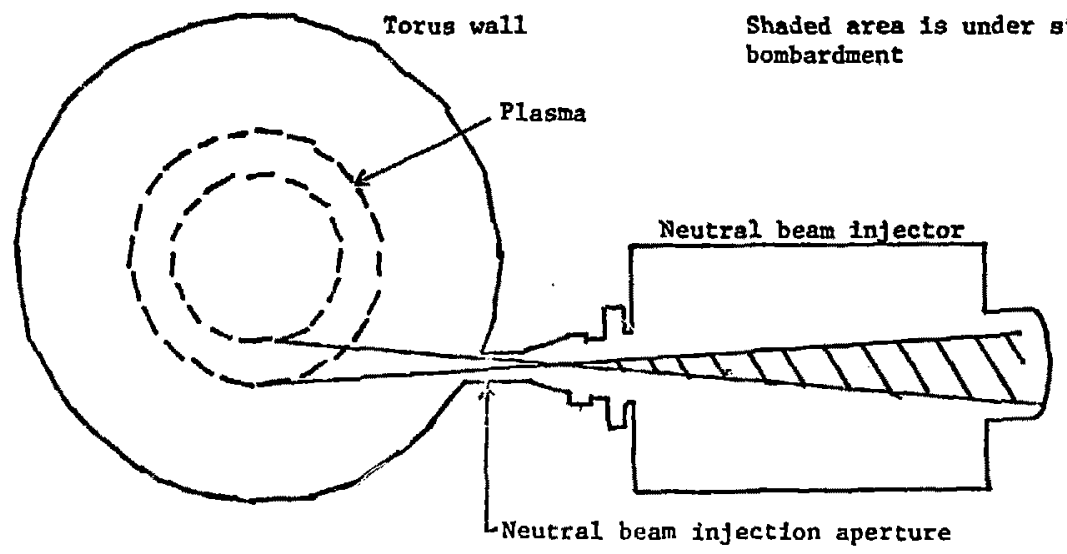

Diagram showing the existence of a neutral beam injection aperture allowing unshielded, unatenuated neutrons to escape

Fig $\cdot 23$ 


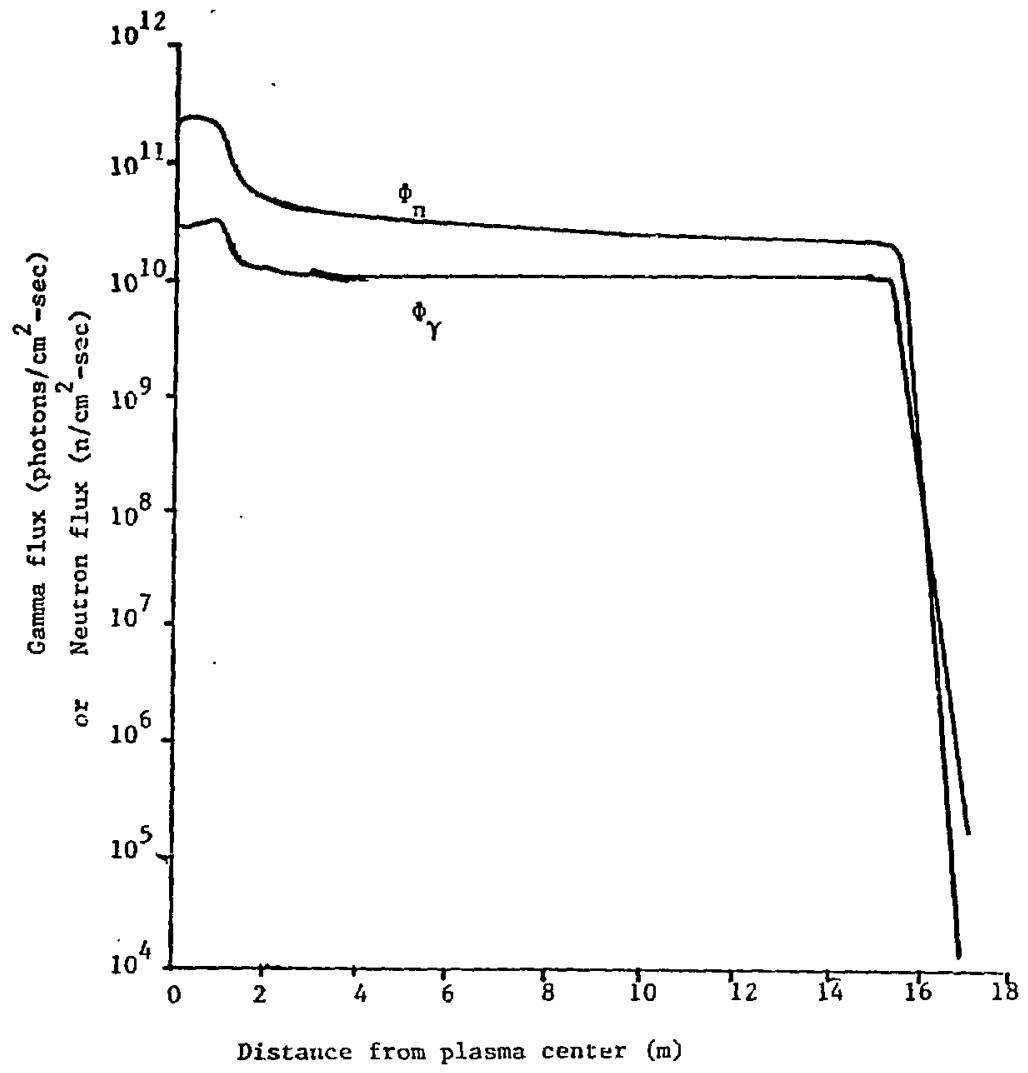

TOTAL NEUTRON AND GARMA FLUX AROUND TFTR (NO SHIELDING)

Fig. 24 


\begin{tabular}{|c|c|c|c|c|c|c|}
\hline Sample & React1on & Product & $t_{1 / 2}$ & Peak counted & $\mathrm{E}_{\mathrm{eff}}(\mathrm{MeV})$ & $\underline{\sigma}$ \\
\hline${ }^{27} \mathrm{AI}$ & $(n, p)$ & ${ }^{27} \mathrm{Mg}$ & $9.5 \mathrm{~m} / \mathrm{n}$ & $1.013(30 z)$ & 3.3 & $3.1 \mathrm{mb}$. \\
\hline${ }^{27} \mathrm{AI}$ & $(n, \alpha)$ & $24 \mathrm{Na}$ & $15 \mathrm{hr}$. & $1.37(100 \%)$ & 8.7 & $0.48 \mathrm{mb}$ \\
\hline${ }^{115} \mathrm{In}(\mathrm{Cd})$ & $\left(n, n^{\prime}\right)$ & $115 \mathrm{~m}_{\mathrm{In}}$ & $4.5 \mathrm{hr}$. & $0.335(50 \%)$ & 1.0 & $171 \mathrm{mb}$ \\
\hline${ }^{197} \mathrm{Au}$ & $(n, \gamma)$ & ${ }^{198} \mathrm{Au}$ & 2.7 Day & $0.412(95 \%)+\beta$ & $0.25 \mathrm{eV}$ & $87 \mathrm{~b}$ \\
\hline${ }^{197} \mathrm{Au}$ & $(n, \gamma)$ & ${ }^{198} \mathrm{Au}$ & 2.7 day & $0.412(95 \%)+B$ & $0.25<\mathrm{E}<0.4 \mathrm{eV}$ & $87 \mathrm{~b}$ \\
\hline
\end{tabular}

Fig. 25 LIST OF FOIL MATERIALS USED FOR NEUTRON SPECTRUM MEASUREMENT 


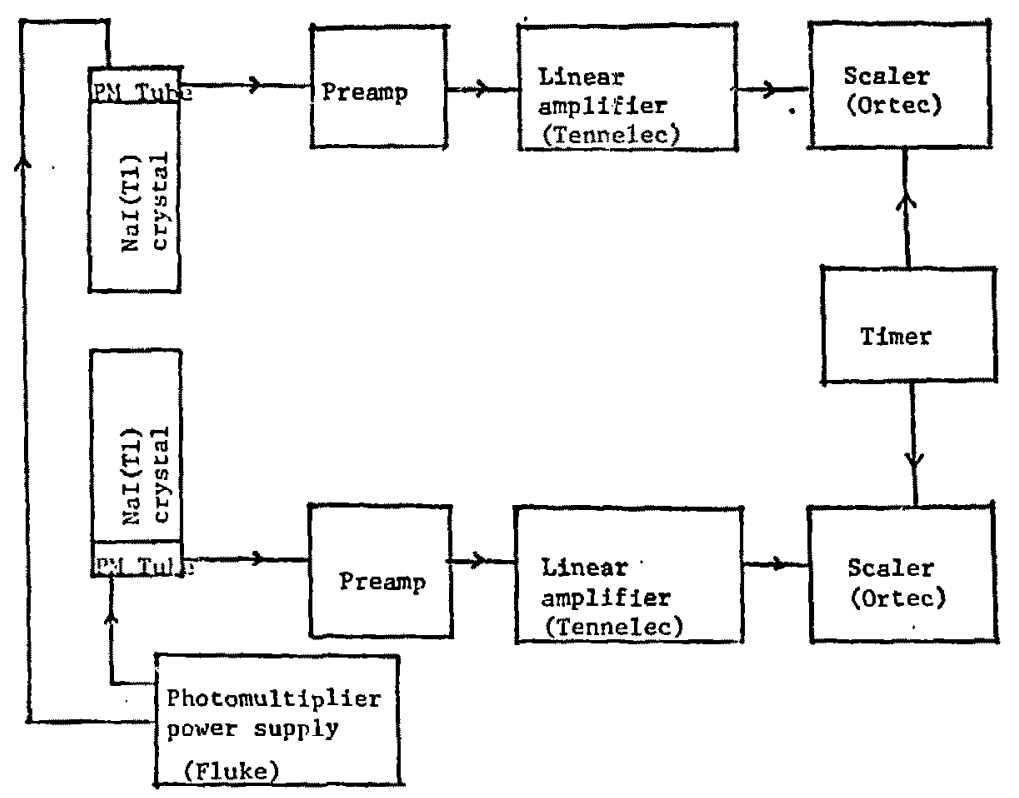

SCHEMATIC OF NaI(TI) SCINTILLATION COUNTER

Fig. 26 


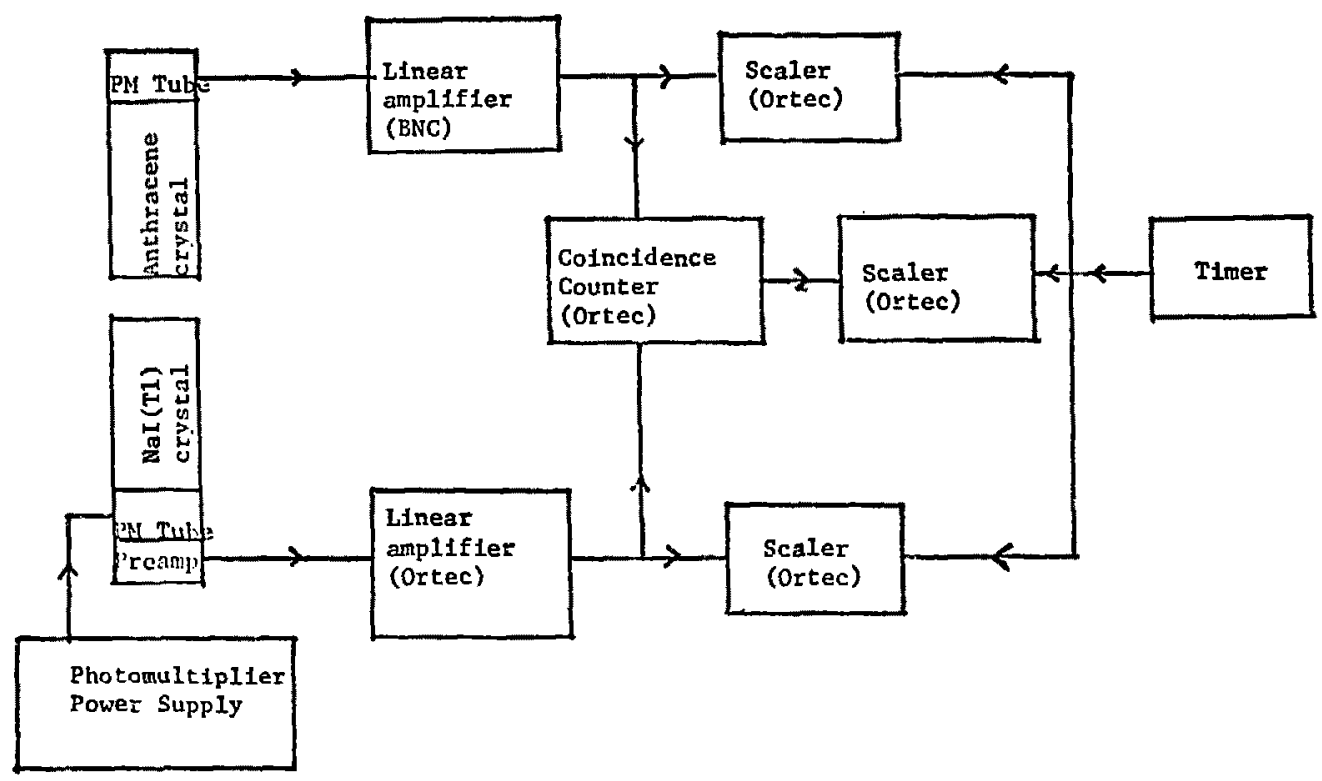

SCHEMATIC OF $\beta-\gamma$ COINCIDENCE COUNTER

Fig. 27 


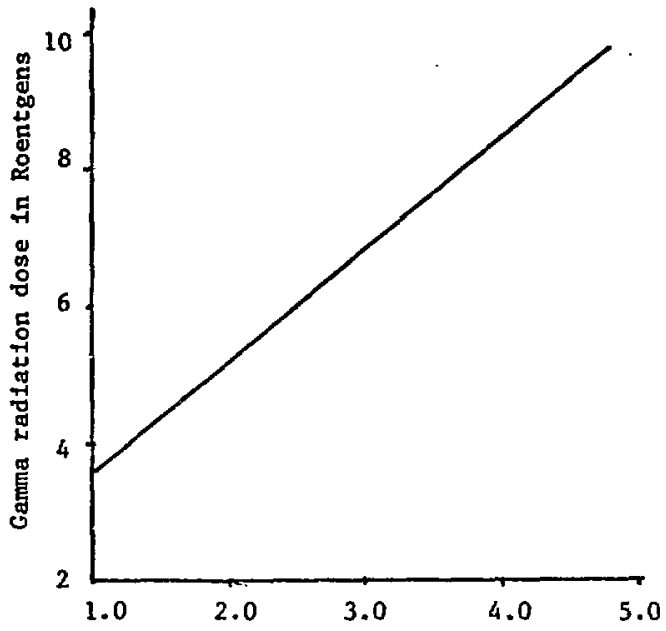

Background corrected TLD reading in $\mu \mathrm{C}$

CALIBRATION FOR THERMOLUMINESCENT DOSINETER

LIGHT OUTPUT vs. DOSE

Fig . 28 


\begin{tabular}{|c|c|c|}
\hline Fo11 & Energy Range & Neutron flux (n/cm $\left.{ }^{2}-p u l s e\right)$ \\
\hline${ }^{115}$ In (Cd) & $>1 \mathrm{MeV}$ & $1.91 \times 10^{12}$ \\
\hline${ }^{27} \mathrm{Al}$ & $>3.3 \mathrm{MeV}$ & $1.14 \times 10^{12}$ \\
\hline${ }^{24} \mathrm{Na}$ & $>8.7 \mathrm{Mev}$ & $5.80 \times 10^{12}$ \\
\hline${ }^{198} \mathrm{Au}$ & thermal & $1.10 \times 10^{11}$ \\
\hline Method & Energy Range & Gamma Flux (phorons/ $/ \mathrm{cm}^{2}$-pulse) \\
\hline & Entlre spectrum & $2.16 \times 10^{1}$ \\
\hline
\end{tabular}

RESULTS OF A REACTOR PULSE MEASUREMENT USING THE FOIL ACTIVATION METHOD

Fig. 29 


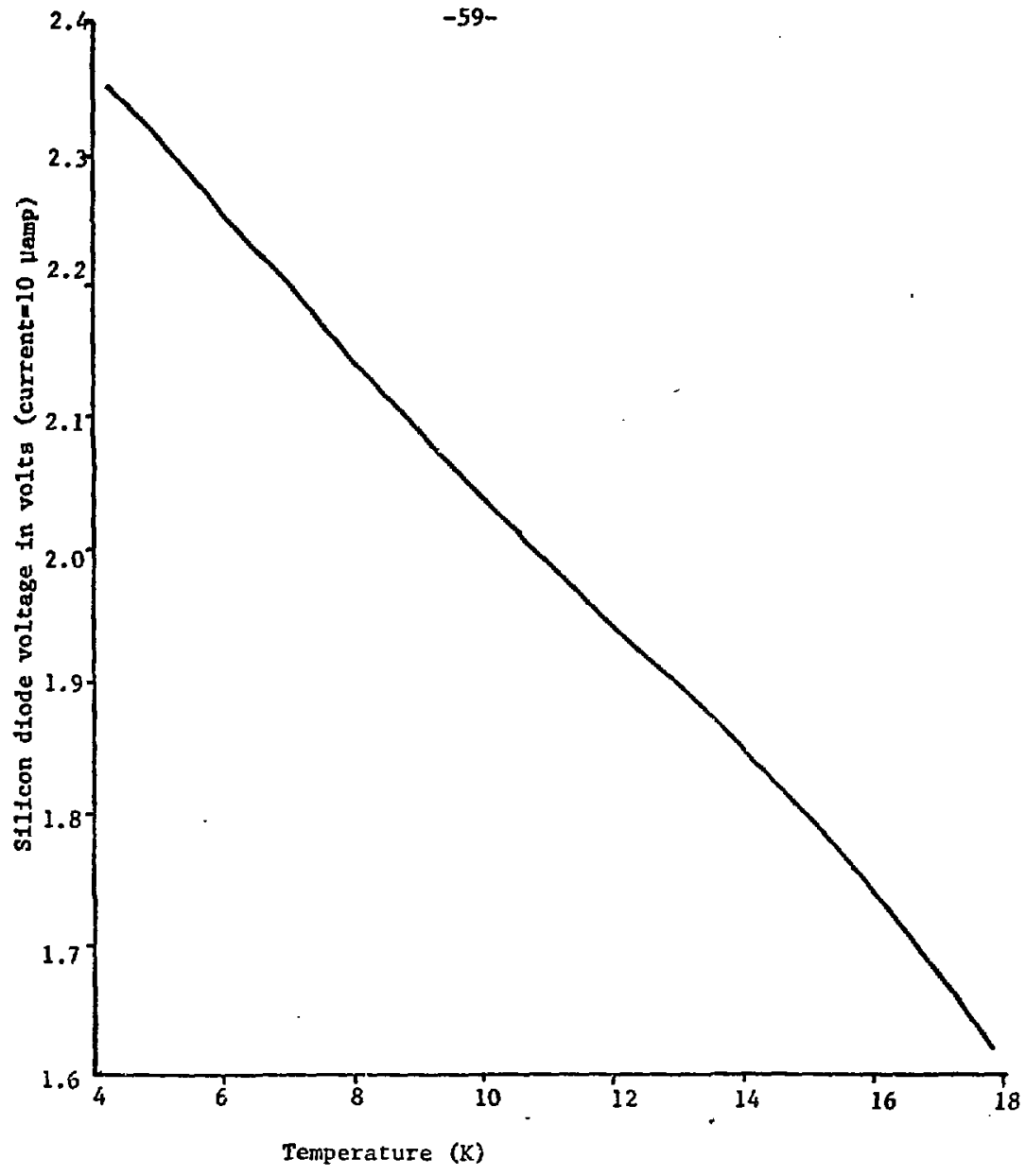

SILICON DIODE TEMPERATURE-VOLTAGE CURVE

Fig. 30 
EMP. CALIBR. EASED CN $-3250 E+03$ CHIAS AT - $253 E+03$ AND .4160E+03 CHASS AT .770E+02 AND .5722E404 OHMS AT .420E+O1

Is en.45

T IN KFLVIN

R IN CIIMS

T IN KELVIN

R IN OHMS

$\boldsymbol{T}$

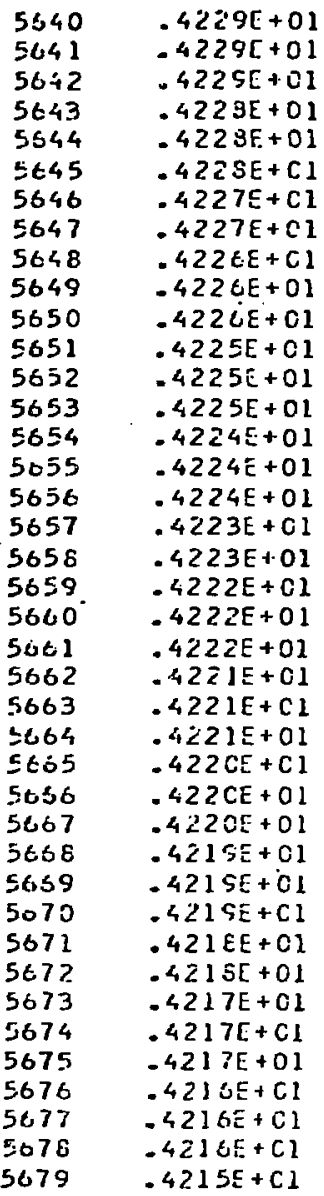

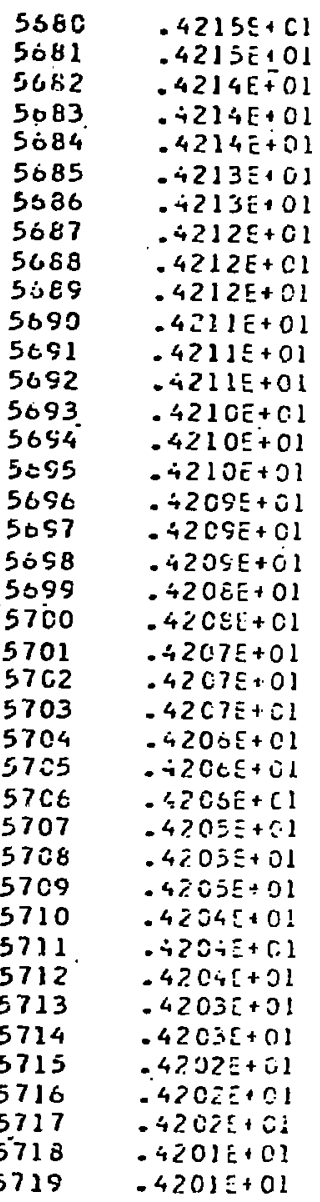

h

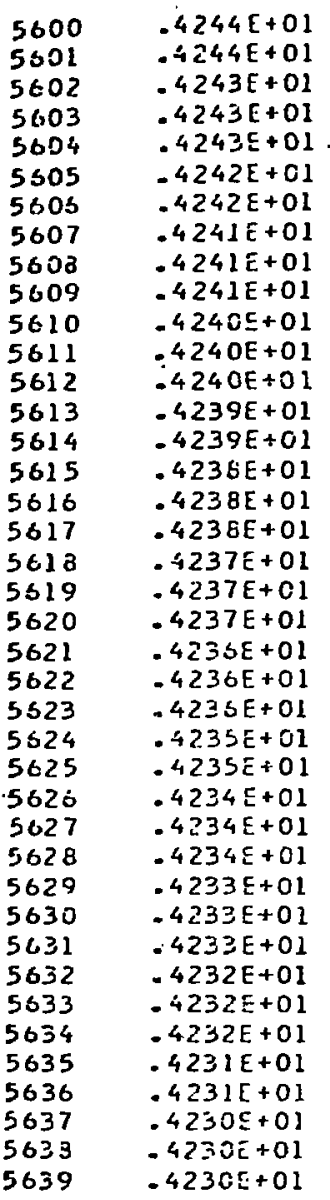

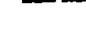




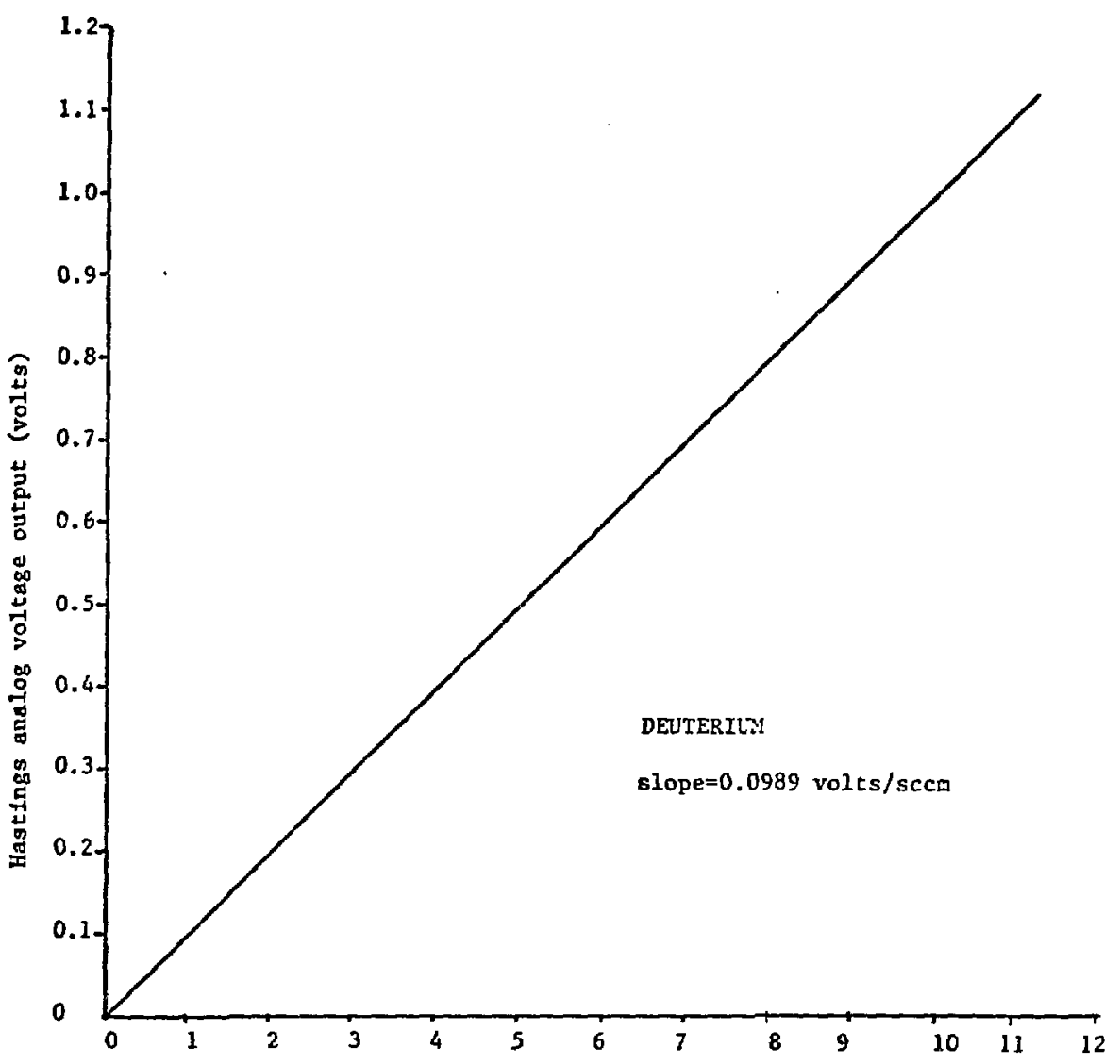

Flowt ate in SCCM

Fig. 32 HASTINCS FLOMETER CALIBRATION (ANALOC OLTPUT vs FLOWRATE' AS MEASURED BY THE MERCURY BUEEIE LEAK) 


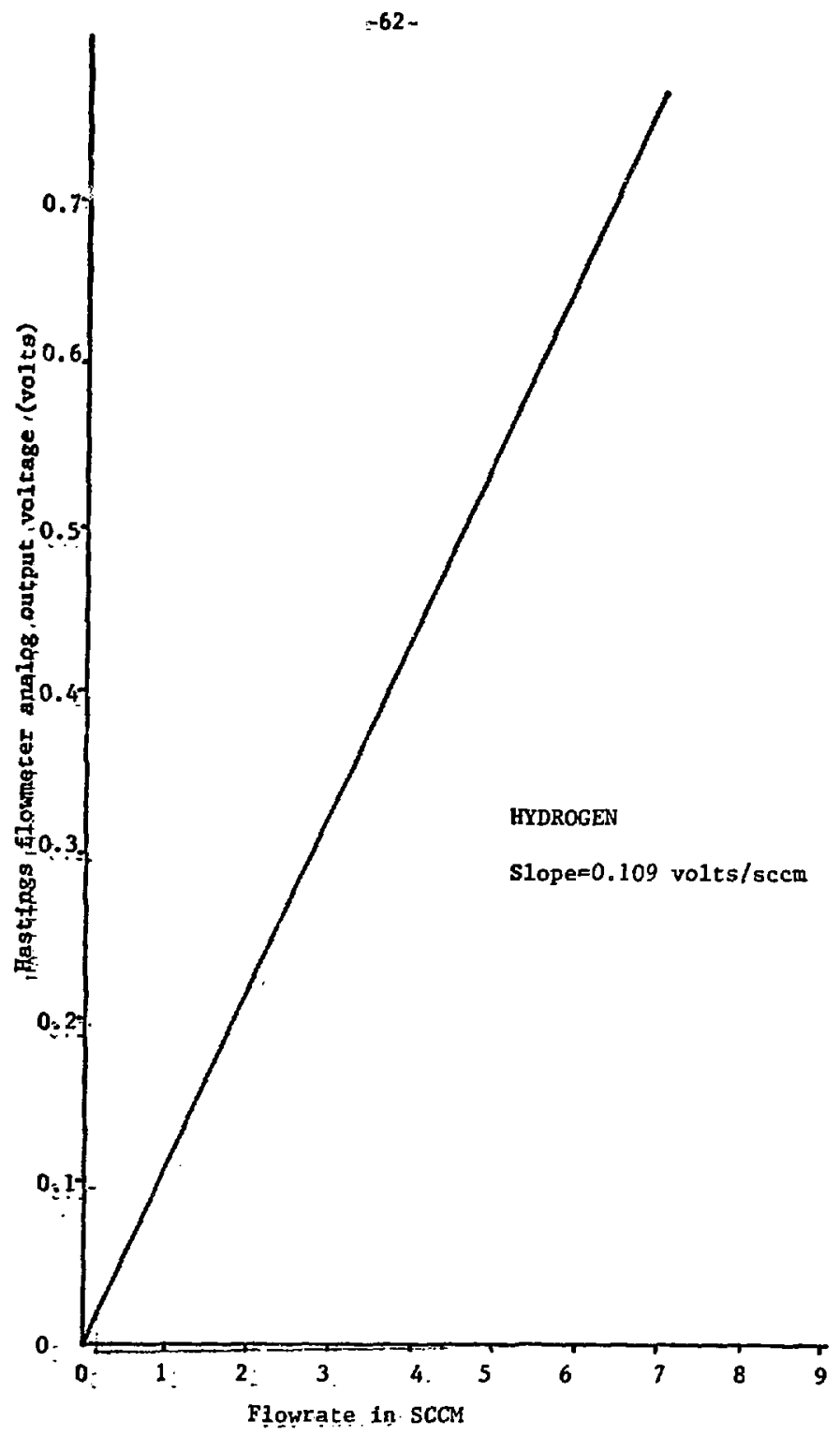

HASTINGS -FLOWRETER CALIBRATION (ANALOS OUTPUT VS FLONRATE AS MEASURED BY THE MERCURY BUBBLE LEAK)

Fig. 33 


\section{REFERENCES}

1. M. Kaminsky, S.K. Das and P. Souze. "Neutron Sputtering of Solids," in Advances in Chemistry Series 158, R.F. Gould, ed. (American Chemical Soclety, Washington, D.C., 1976).

2. M.J. Drinkwine, Y. Shapira and D. Llchtman. "Electron and Photon-induced Desorption," In Advances in Chemistry Series 158, R.F. Gould, ed. (American Chemical Society, Washington, D.C., 1976).

3. M. Borghi and B. Ferrario. J. Vac. Sci. Tech. 14, 570 (2977).

4. R. Colder and G. Lewin. Brit, J. Aoplied Physies 18, 2459 (i967).

5. K.H. Berkner, et al. Cryopump, Heutral-Zeam Compatibility

Test. Lawrence Eerkeley Laboratory, LBL-5943 (1977).

6. H.J. Halama. AGS Division $\mathrm{H}^{-}$Technical Note No. 4. Accelerator Division, Brookhaven Natlonal Laboratory, Upton, New York (1974).

T. J.T. Hogan and H.C. Howe. J. Of Nuclear Materials 63,151 (]976).

8. T. Kammash. Fusion Reactor Physics (Ann Arbor Science, Ann Arbor, Mich., 1976). 
9. D.M. Meade. Nuclear Fusion 14, 289 (1974).

10. W.J. Karzas and R. Latter. Astrophy. J. Suppl. 55 (6), 267 (1961)

11. R.F. Post. I. Nucl. Energy 3, 273 (1961).

12. E. Hinnov. Princeton Plasma Physics laboratory, MATT-777 (2970).

13. D.E. Post, et al. Princeton Plasma Physics Laboratory. MATT-1262 (1976).

14. J.P. Girard, D.A. Marty and P. Moriette. Proceedings of the First International Conference on Plasma Physics and Controlled Fusion Research (IAEA, Vienne, 1975) p. 681.

15. D.L. Jassby. Nuclear Fusion 17 (2), 309 (197?).

16. R. Kelly and N.Q. Lem. Rad. Effects 19, 39 (1973),

17. W.M. Tang, P.H. Rutherford, K.P. Furth, and J.C. Adams. Phys. Rev. Lett. 35, 660 (1975).

18. T. Ohkawa. Kakuyugo Kenizu 32 32,67 (1974).

19. LBL/LLL CTR Staff. LBL-3296, Lawrence Berkeley Laboratory (1975).

20. T.J. Duffy and L.D. Oddon. Lawrence Livermore Laboratory, UCRL-77236 (1975).

21. C. Benvenuti and R.S. CaIder. CERN Report, CERN-ISR-VA/69-78.

22. T.J. Lee. Nat. Phys. Sci.231 (26), 193 (1971).

23. C. Benvenuti, R.S. Calder and G. Pasardi. J. Vac.Sci. Tech. $13(6), 172(1976)$. 
24. S.K. Erents and G.M. McCracken. J. Appl. Phys. 44 (7), 3139 (1973).

25. L.C. Dittenger. Lawrence Livernore Laboratory, UCRL-78501 (1976).

26. J. Haughian. Lawrence Berkeley Laboratory, Mechanical Engineering Note CT 0301, M4918.

27. H.M. Roder, G.E. Childs, R.D. McCarty and P.E. Augerhoter. Nat. Bur. of Stend. Tech. Note 64I (U.S. Government Printing Orfice, Washington, D.C. 1973).

28. C.K. Briggs, et al. Lawrence Livermore Laboratory, UCR. 76700 (1975).

2'. E.E. Anderson. Modern Physics ana Quantum Mechanics

(W.B. Saunders, Philadelphia, PA, I971).

30. D. McCarthy. Hydrogen Technolosies? Survey-Thermophysical

Properties, NASA Report, SP-3089 (HASA, Lewis Research Center, Washiniton, NASA, 2975).

31. W.J. Moore. Prisical Chemistry 4th ed. (Prentice-Hall, New York, N.Y., 1973).

32. D.E. Miller. I. Chem. Pinys. 42, 2089 (1965).

33. R.L. Mills and A.F. Shuck. Phys. Rev. Letters 15, 722 (1965).

34. K.F. Mucker, S. Talhouk, P.M. Harris, D. White, and R.A. Erikson. Phys. Rev. Letters 15, 586 (1965). 
35. H.J.Halama, C.K. Lam and J.A. Bamberger. J.Vec. Se1. Tech. $14(5), 1201(1977)$.

36. L.E. Velby. Lawrence Livermore Laboratory, UCRL-79708 (1977).

37. A.R. Sweedlar, et al. In Radiation Effects end Tritiue

Technniogy For Fusion Reactors. CONF-750989 (Oak Ridge

Mational Laboratory, Tennessee, 1975).

38. M. Soell in Eighth Sympostun on Fusion Techrology (Buratom, Brussels, Belgium, 1974).

39. J.E. Faulkner, G. Gibson and J. Jedruch. Westinghouse Electric Corporation Report, WFPS-TME-022, 1975.

40. M.W. Thompson. Defects and Radiation Damage in Metals. (Cambriage Inivarsity Press, Cambridge, 1969).

41. A. Seeger in Proceedings of the Second United Tations International Conserence on the Peaceful Uses of Atomic Energy, Geneva, 1958, 6, 250 (United Nations, N.Y., 1958).

42. Reference letter dated November 24, 1967 to L. Stoller, UCB. Private comminications.

43. A. Calamand. "Fission Neutron Averaged Cross-Sections" in Handbook on Yuclear Activation Cross-Sections (IAEA, Vienna, 1974).

44. J.R. Clemment and E.H. Quinnell. Rev. of Sei. Instr. 23 (5), $213(1952)$. 